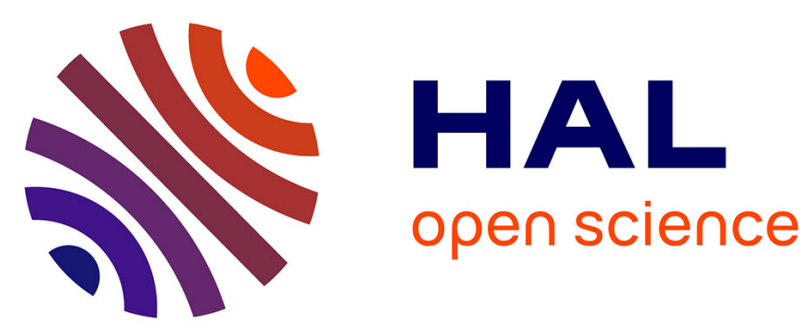

\title{
Oxidized Titanium Tungsten Surface Functionalization by Silane-, Phosphonic Acid-, or Ortho-dihydroxyaryl-Based Organolayers
}

Jian Zhang, Christelle Yeromonahos, Didier Léonard, Thomas Gehin, Claude Botella, Geneviève Grenet, Aziz Benamrouche, Jose Penuelas, Stéphane Monfray, Yann Chevolot, et al.

\section{To cite this version:}

Jian Zhang, Christelle Yeromonahos, Didier Léonard, Thomas Gehin, Claude Botella, et al.. Oxidized Titanium Tungsten Surface Functionalization by Silane-, Phosphonic Acid-, or Ortho-dihydroxyarylBased Organolayers. Langmuir, 2019, 35 (29), pp.9554-9563. 10.1021/acs.langmuir.8b04150 . hal02187637

\section{HAL Id: hal-02187637 https://hal.science/hal-02187637}

Submitted on 10 Jun 2021

HAL is a multi-disciplinary open access archive for the deposit and dissemination of scientific research documents, whether they are published or not. The documents may come from teaching and research institutions in France or abroad, or from public or private research centers.
L'archive ouverte pluridisciplinaire HAL, est destinée au dépôt et à la diffusion de documents scientifiques de niveau recherche, publiés ou non, émanant des établissements d'enseignement et de recherche français ou étrangers, des laboratoires publics ou privés. 


\section{Oxidized titanium tungsten surface}

\section{functionalization by silane, phosphonic acid or}

\section{ortho-dihydroxyaryl based organolayers}

Jian Zhang, ${ }^{\dagger}$ Christelle Yeromonahos, ${ }^{\dagger}$ Didier Léonard, ${ }^{\star}$ Thomas Géhin, ${ }^{\dagger}$ Claude Botella, ${ }^{\dagger}$

Geneviève Grenet, ${ }^{\dagger}$ Aziz Benamrouche, ${ }^{\dagger}$ José Penuelas, ${ }^{\dagger}$ Stéphane Monfray, ${ }^{\S}$ Yann Chevolot, $^{\dagger *}$ and Jean-Pierre Cloarec ${ }^{\dagger *}$

† Université de Lyon, Institut des Nanotechnologies de Lyon (INL) - UMR CNRS 5270, Ecole Centrale de Lyon, 36 Avenue Guy de Collongue, 69134 Ecully cedex, France.

Univ Lyon, CNRS, Université Claude Bernard Lyon 1, ENS de Lyon, Institut des Sciences Analytiques, UMR 5280, 5, rue de la Doua, F-69100 Villeurbanne, France.

${ }^{\S}$ STMicroelectronics SA, 850, rue Jean Monnet, 38926, Crolles, France.

Corresponding authors:

Jean-Pierre Cloarec jean-pierre.cloarec@ec-lyon.fr

Yann Chevolot yann.chevolot@ec-lyon.fr

KEYWORDS. titanium tungsten; TiW; titanate; silane; phosphonic acid; catechol; organolayers; functionalization; XPS; ToF-SIMS; nanoelectronics; stability. 
ABSTRACT. $200 \mathrm{~nm}$ thick films of titanium tungsten (TiW) were cleaned by oxygen plasma and the resulting oxidized surfaces were functionalized by 3-aminopropylphosphonic acid (APPA), 3-ethoxydimethylsilylpropylamine (APDMES) or dopamine (DA) to form three different organolayers. The three resulting organolayers were characterized by X-ray photoelectron spectroscopy (XPS), Time-of-flight secondary ion mass spectrometry (ToFSIMS) and Fourier transform infrared spectroscopy (FTIR) analysis. Stability of each organolayer was investigated. Our results suggested that the $\mathrm{Si}-\mathrm{O}-\mathrm{Ti}$ or $\mathrm{Si}-\mathrm{O}-\mathrm{W}$ bonds issued from the reactions of APDMES with surface oxidize TiW were rather labile whereas the catechol layer was less labile. The APPA layer was the most stable of all tested surface modifications.

Introduction

Surface chemical functionalization of inorganic materials has been developed for various applications, such as surface patterning fabrication, ${ }^{1}$ tissue engineering, ${ }^{2}$ biosensors ${ }^{3}$ and corrosion inhibition. ${ }^{4}$ Surface chemical functionalization can be achieved either using polymeric material deposition or by the attachment of low molecular weight functional molecules bearing a chemical group that can react with the surface of the materials (substratebinding head group) to form an organolayer.

The development of new generations of ISFETs based on up-to-date nanoelectronic devices is currently being explored. Industrially produced Fully Depleted Silicon On Insulator (FDSOI) structures are for instance being explored for ultrasensitive detection of chemical species. 5,6 Such FDSOI structures could also be used as transducers in ultrasensitive BioFETs. BioFETs classically require to elaborate a first organolayer onto the transducer surface, followed by grafting of biomolecular probes. In order to be of interest to nanoelectronic companies, the formation of organolayers needs to be implemented on materials used by this industry. Among 
materials classically used for elaborating nanoelectronic devices in the Back end of line (BEOL), gold is considered as a contaminant for electrical contacts and is avoided. TiW is commonly used in nanoelectronic architectures, thanks to its excellent fabrication reproducibility. It is classically used as diffusion barrier and is considered as very stable ${ }^{7-15}$. Specialists of nanoelectronic industry consider TiW oxide surface as particularly stable, from structural and chemical point of views, even on a long term. This type of surface therefore exhibits a strong potential for industrially produced chemical sensors and biosensors based on nanoelectronic transducers. However, despite the fact that the surface modification of titanium oxide has been widely described, and the one of tungsten oxide has been scarcely reported, to the best of our knowledge, surface chemical functionalization of TiW has never been reported. ${ }^{16,17}$

In this context, this study concerns the formation of organolayers on $200 \mathrm{~nm}$ thick TiW films deposited on silicon wafers. Since titanium and tungsten are prone to form oxide layers, we first assessed that a surface oxide layer is indeed present after plasma oxygen cleaning. Next, we compared the formation of organic layers on plasma cleaned TiW using organosilane, phosphonic acid and ortho-dihydroxyaryl compounds. Indeed, these binding head groups have been reported for the formation of organolayers on oxides. ${ }^{18}$ Three molecules: 3aminopropylphosphonic acid (APPA), 3-ethoxydimethylsilylpropylamine (APDMES), dopamine (DA) were used. Nitrogen was used as an elemental reporter (elemental signature of the molecules). The three layers were characterized by X-ray photoelectron spectroscopy (XPS), Time-of-flight secondary ion mass spectrometry (ToF-SIMS) and Fourier transform infrared spectroscopy (FTIR). Finally, their stability in aqueous medium was compared.

Experimental section

Materials 
200-nm thick TiW layers was prepared by STMicroelectronics on silicon substrate. Chemicals were commercially available. Reagent or higher grade chemicals were used. Dopamine hydrochloride 97\% (DA) and 3-aminopropylphosphonic acid (APPA) 97\% were purchased from Sigma-Aldrich. (3-aminopropyl)-dimethylethoxysilane (APDMES) 99.9\% was purchased from abcr GmbH. The chemical structures of the three molecules are shown in Scheme 1. Dichloromethane (DCM) 99.9\% was purchased from Sigma-Aldrich and dried over molecular sieves before use. The deionized water (18.2 M $\Omega)$ used for all the experiments was obtained using a VEOLIA purelab water system.

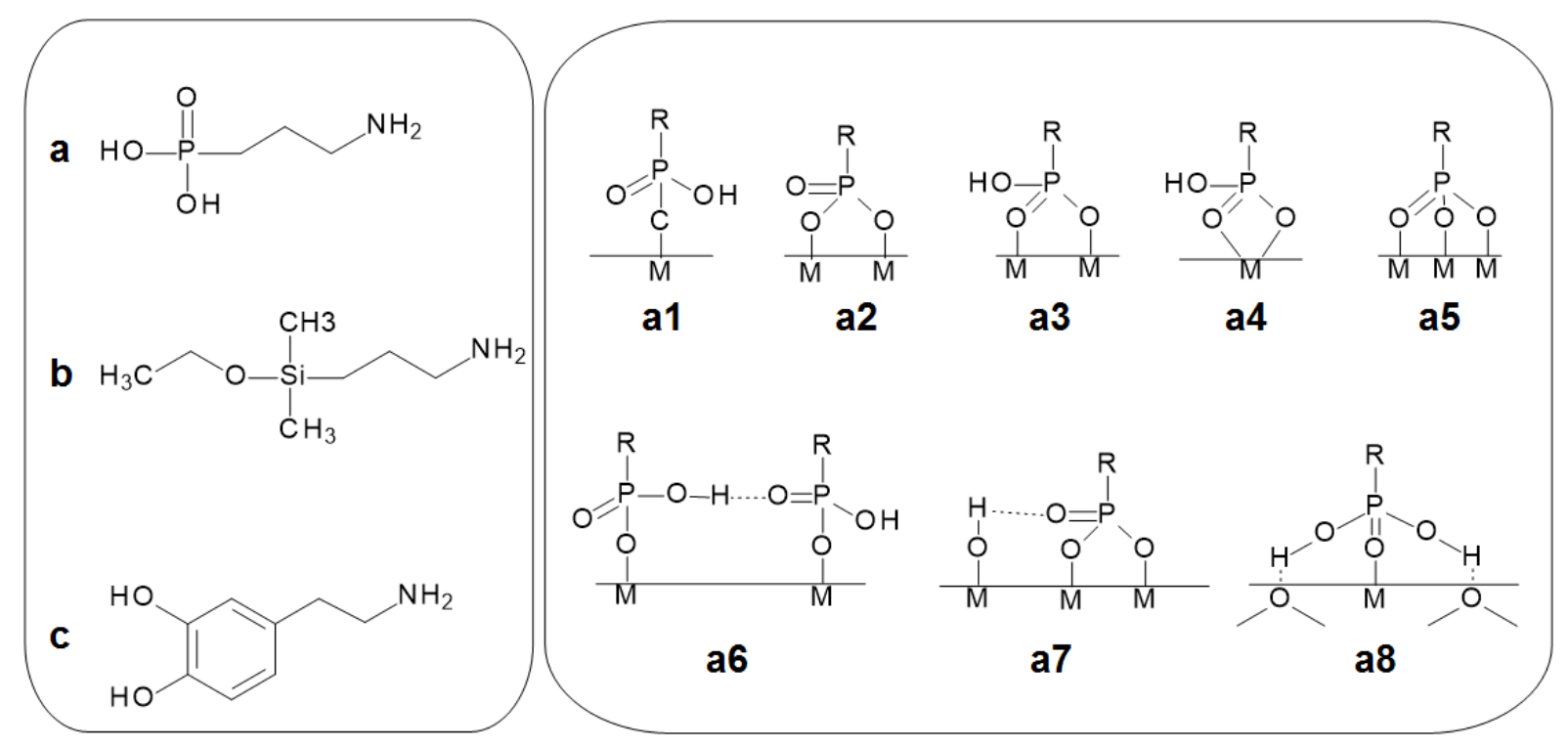

Scheme 1. Chemical structures of (a) APPA, (b) APDMES and (c) DA. Right: examples of possible binding modes of APPA with metal: (a1) monodentate APPA; (a2, a3) bridging bidentate APPA ; (a4) chelating bidentate ; (a5) bridging tridentate ; (a6, a7, a8) additional hydrogen-bonding interactions. (after Brodard-Severac et al. ${ }^{19}$ ).

Surface functionalization

The substrates were cleaned by oxygen plasma treatment (Anatech) at $400 \mathrm{sccm}$ of oxygen, $350 \mathrm{~W}$ of forward power (10 $\mathrm{W}$ reflected power) for $5 \mathrm{~min}$ to remove organic contamination 
and to obtain a hydroxyl-terminated surface. Herein TiW functionalized by APPA, APDMES and DA organolayers are named by APPA-TiW, APDMES-TiW and DA-TiW, respectively. Following $\mathrm{O}_{2}$ plasma treatment, organolayers were formed by following protocols for APPA ${ }^{20}$ APDMES ${ }^{21}$ and $\mathrm{DA}^{22}$ previously assessed in the literature:

- APPA-TiW: substrates were immersed in $10 \mathrm{mM}$ APPA aqueous solution for 24 hours. The samples were then washed with ultrapure water for 5 min under sonication rinsed with a stream of ultrapure water and dried with a nitrogen flow.

- APDMES-TiW: substrates were immersed in $25 \mathrm{~mL}$ dried DCM containing $10 \mu \mathrm{L}$ APDMES (3mM) for 48 hours. The samples were then rinsed with fresh DCM for 5 min under ultrasound (Branson, $42 \mathrm{kHz}, 100 \mathrm{~W}$ ) followed by a stream of ultrapure water and dried with a nitrogen flow.

- DA-TiW: substrates were immersed in a $0.5 \mathrm{mg} / \mathrm{mL}$ degassed DA aqueous solution for 24 hours under nitrogen. The samples were then washed with ultrapure water for $5 \mathrm{~min}$ under sonication, rinsed with a stream of ultrapure water and dried with a nitrogen flow.

Organolayers stability study

APPA-TiW, APDMES-TiW, and DA-TiW were immersed in ultrapure water and incubated at $70{ }^{\circ} \mathrm{C}$ for $0,15,30$ or 60 minutes. After removal from the hot water, the samples were rinsed in room temperature ultrapure water and were dried with a nitrogen flow.

\section{Characterization}

The crystal structure of the materials was characterized by X-ray diffraction (XRD) using a Rigaku Smartlab diffractometer with a rotating anode (power=9kW). The source $\mathrm{CuK}$ radiation was monochromatized by a double Ge (220) crystal to select the $\mathrm{CuK} \alpha_{1}$ ray $(\lambda=0.15406 \mathrm{~nm})$. The detector was a point scintillation counter. X-ray diffraction measurements were performed 
with a diffractometer equipped with a rotating anode operating at $9 \mathrm{~kW}$ monochromatized with a two reflection $\mathrm{Ge}(220)$ crystal which selects the $\mathrm{Cu} \mathrm{K \alpha 1}$ radiation (wavelength $=1.5406 \AA$ ). The detector was a scintillation counter. The measurements were performed by varying the Bragg angle between $2 \theta=10^{\circ}$ and $2 \theta=80^{\circ}$, the step size was set to $0.01^{\circ}$ and the scan speed was set to $3 \%$ minute.

The surface topography of oxidized TiW was monitored using a SMENA B (NT-MDT) AFM microscope in the tapping modulation (AM) mode with Mikromash XSC11 with Al backside tips (resonance frequency $=80 \mathrm{kHz}$ ). The data analysis was performed with Gwyddion Software.

Attenuated total reflectance Fourier transform infrared spectroscopy (ATR-FTIR) was performed using a Thermo Nicolet 6700 spectrometer with MCT detector (Electron Corporation, USA) by a germanium crystal from $800 \mathrm{~cm}^{-1}$ to $4000 \mathrm{~cm}^{-1}$. Results were obtained from averages of 256 scans at a resolution of $4 \mathrm{~cm}^{-1}$.

Time-of-flight secondary ion mass spectrometry (ToF-SIMS) measurements were performed using a Physical Electronics TRIFT III instrument (Physical Electronics, Chanhassen, MN) operated with a pulsed $\mathrm{Au}$ ion gun (ion current of $2 \mathrm{nA}$ ) over a $300 \mu \mathrm{m} \times 300 \mu \mathrm{m}$ area. The ion dose was kept below the static condition limits. Data were analyzed using WinCadence software. Mass calibration was performed on hydrocarbon secondary ions.

X-ray Photoelectron Spectroscopy (XPS) measurements were performed using a VSW spectrometer equipped with a monochromatized X-ray source ( $\mathrm{Al} \mathrm{K} \alpha 1486.6 \mathrm{eV})$ in which the angle between the incident beam and the detector is the magic angle. Its angular resolution is $3^{\circ}$. Take-off angle was $90^{\circ}$ relative to the substrate surface. The energetic resolution was 0.2 $\mathrm{eV}$. The data analysis was performed with CasaXPS software. $\mathrm{W}_{4} \mathrm{f}_{7 / 2}$ binding energy was set at $31.6 \mathrm{eV}$. Full widths at half maximum (FWHM) for the core levels $\mathrm{Si} 2 \mathrm{p}_{3 / 2-1 / 2}, \mathrm{P} 2 \mathrm{p}_{3 / 2-1 / 2}$ were $1.7 \mathrm{eV}$ and $1.9 \mathrm{eV}$, respectively, while FWHMs for the core levels N1s and O1s were 1.7, and 
$1.4 \mathrm{eV}$, respectively. These rather large FWHM values were due to slight charging effects, lack of counting as the samples were sensitive to the beam and longer acquisition times would not be relevant. A Shirley background was subtracted on W4f and Ti2p spectra when coming from bulk elements while a linear background was subtracted on all other spectra when coming from surface elements. Peaks were fitted by a Gauss-Lorentz curve independently but with the atomic ratio and distance of spin-orbit doublets respected: $2.1 \mathrm{eV}$ for $\mathrm{W} 4 \mathrm{f}$ and $6.1 \mathrm{eV}$ for Ti2p.

\section{Results and discussion}

\section{Characterization of $\mathrm{TiW}$ oxidized with $\mathrm{O}_{2}$ plasma}

TiW substrate was studied by XRD, AFM, and XPS after $\mathrm{O}_{2}$ plasma oxidation. The crystal structure of the materials was characterized by X-ray diffraction (XRD) using a Rigaku Smartlab diffractometer with a rotating anode. The XRD pattern (Figure 1) shows a Bragg peak at $2 \theta=39.92^{\circ}$ in agreement with to the TiW bcc phase. ${ }^{5,6,12,15}$ AFM image showed that the TiW surface morphology exhibits small islands about $100 \mathrm{~nm}$ wide and $35-40 \mathrm{~nm}$ high as shown in Figure 2. The Root Mean Square (RMS) was found to be around $3.9 \pm 0.5 \mathrm{~nm}$.

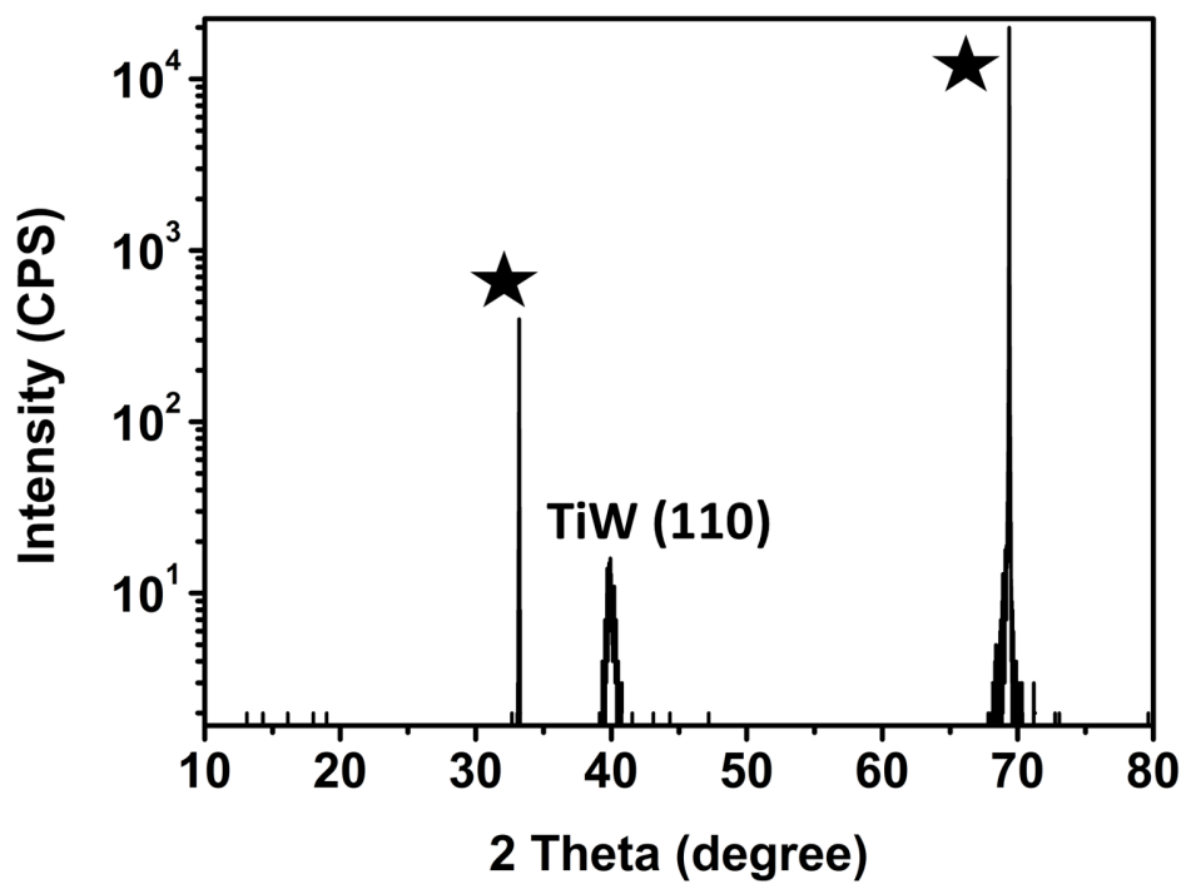

Figure 1. XRD pattern of TiW substrate. Stars correspond to the Silicon substrate. 


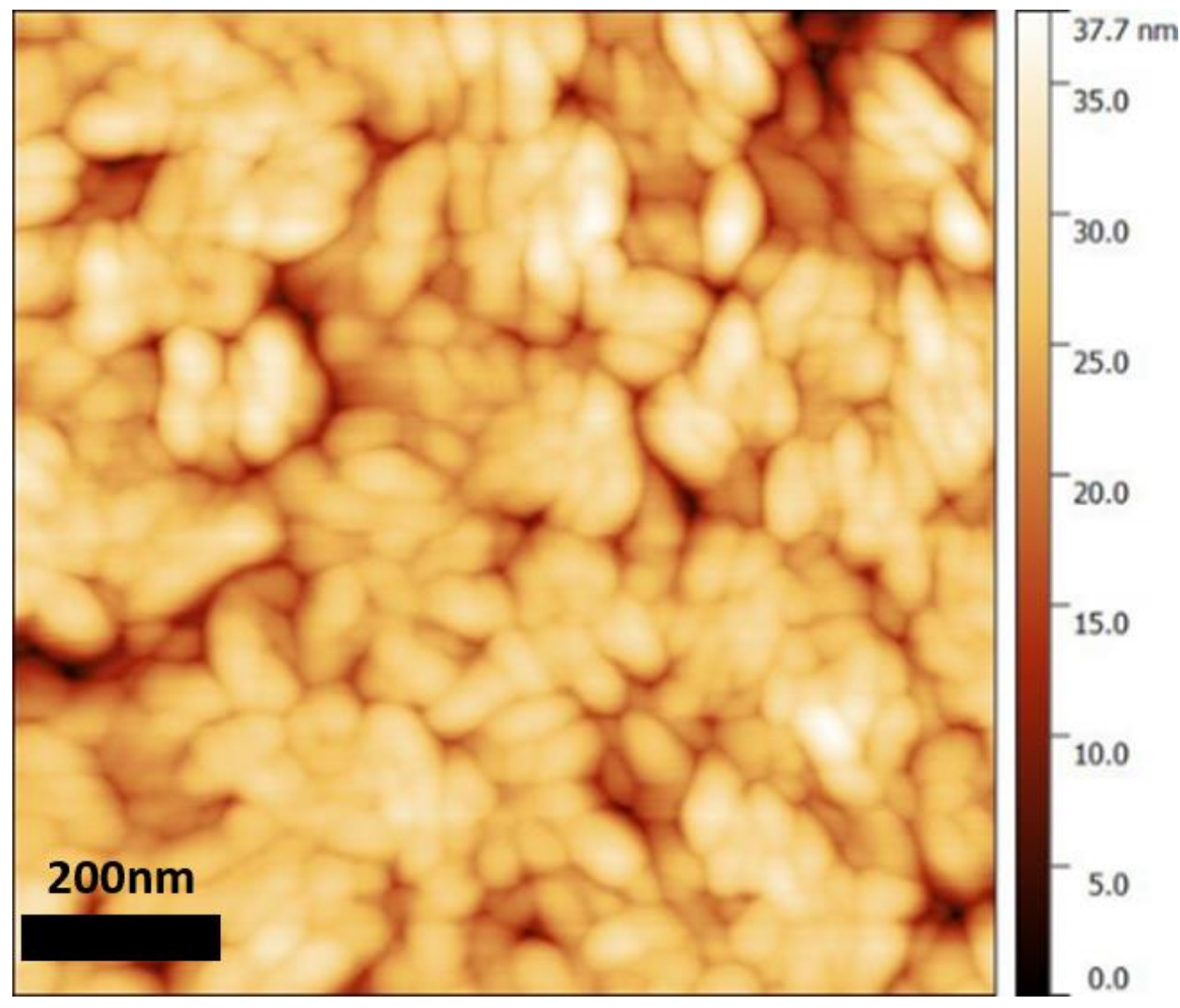

Figure 2. AFM image of TiW substrate.

XPS analysis of the pristine TiW surface showed the presence of carbon. After $\mathrm{O}_{2}$ plasma oxidation the carbon content decreased from $12 \%$ to $10 \%$. Presence of carbon even after $\mathrm{O}_{2}$ plasma is attributed to surface contamination due to atmospheric amorphous carbonated aerosols, since samples are processed in air. ${ }^{23,24} \mathrm{~W} 4 \mathrm{f}$ and Ti2p core levels are shown on Figure 3 and O1s core level on Figure 4. ATR-FTIR spectra of control bare TiW $\left(\mathrm{O}_{2}\right.$ plasma treated oxidized TiW without organolayer) and oxidized TiW modified with APPA, APDMES and DA organolayers are presented in Figure 5. 

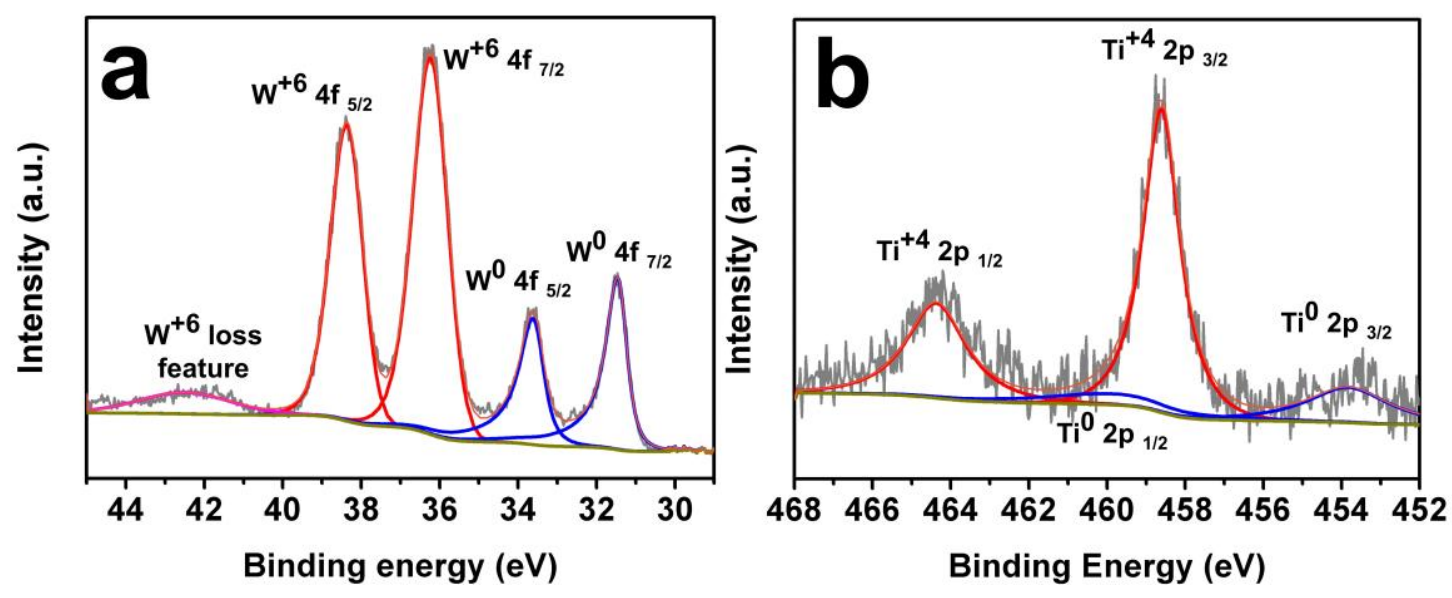

Figure 3. W $4 \mathrm{f}$ core level (a) and Ti 2p core level (b) of the control TiW.

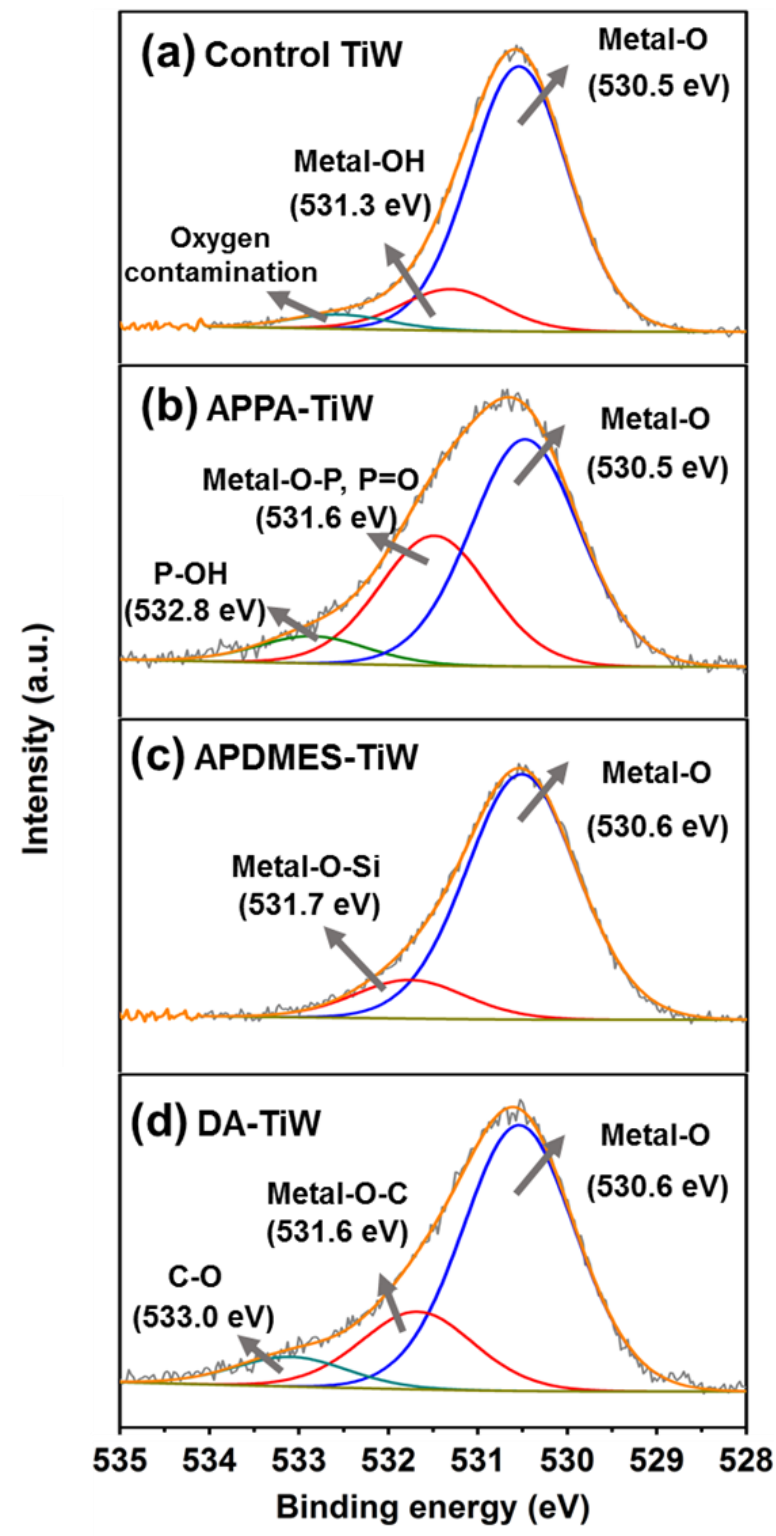

Figure 4. O1s components of (a) control TiW,

(b) APPA-TiW, (c) APDMES-TiW and (d) DA-TiW. 

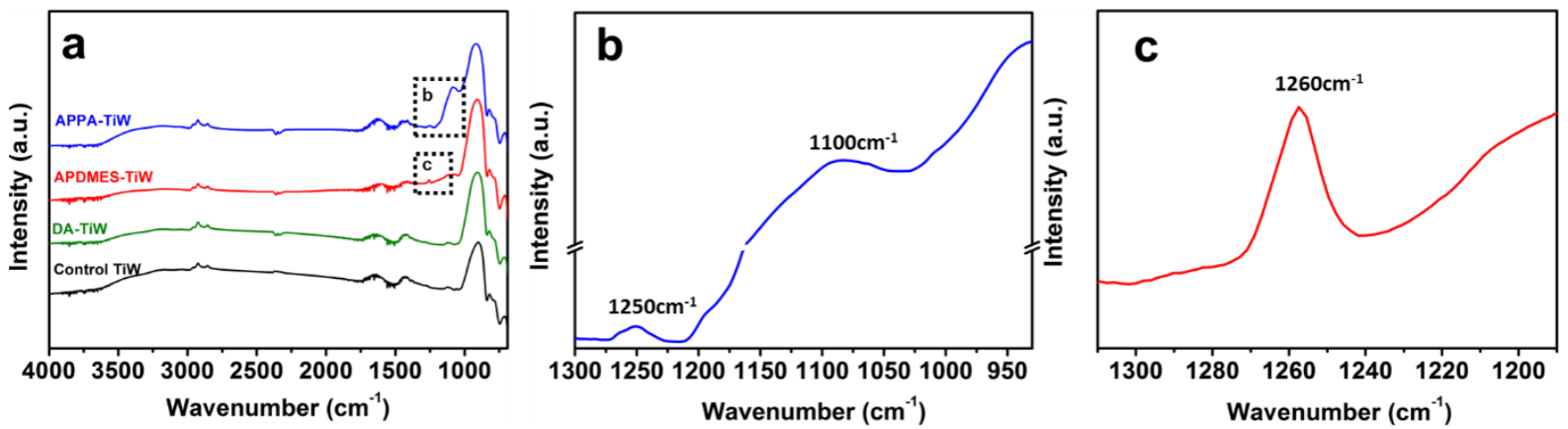

Figure 5. (a) ATR-FTIR spectra of control oxidized TiW (no organolayer) and TiW modified with APPA, APDMES and DA. (b) Enlarged spectrum of the APPA-TiW substrate from 950 $\mathrm{cm}^{-1}$ to $1300 \mathrm{~cm}^{-1}$. (c) Enlarged spectrum of the APDMES-TiW substrate from $1300 \mathrm{~cm}^{-1}$ to $1200 \mathrm{~cm}^{-1}$.

Atomic percentages of the different elements, obtained from XPS analysis, are reported in Table 1, while normalized area of O1s component are reported in Table 2. Survey spectra of plasma-oxidized TiW surface after plasma cleaning are reported on Figure S1: neither P, Si nor $\mathrm{N}$ is detected. On Figure 3a, for plasma oxidized TiW substrate $\mathrm{W} 4 \mathrm{f}_{7 / 2}$ and $\mathrm{W} 4 \mathrm{f}_{5 / 2}$ appear at $31.6 \mathrm{eV}$ and $33.7 \mathrm{eV}$ as expected for metallic $\mathrm{W}^{0}$ in $\mathrm{TiW}$. This $\mathrm{W}_{4} \mathrm{f}_{7 / 2}$ from the substrate at $31.6 \mathrm{eV}$ will be set as the binding energy reference in the following. The presence of welldefined doublets located at $36.1 \mathrm{eV}$ and $38.2 \mathrm{eV}$ along with a broad feature at higher binding energy typical of $\mathrm{W}^{6+}$ state in oxides is consistent with an oxidized TiW surface. ${ }^{25,26}$ In Figure 3b, Ti2 $\mathrm{p}_{3 / 2}$ and Ti2 $\mathrm{p}_{1 / 2}$ with binding energies of $458.6 \mathrm{eV}$ and $464.4 \mathrm{eV}$ correspond to $\mathrm{Ti}^{4+}$ state in oxides while two other peaks observed at $453.7 \mathrm{eV}$ and $459.7 \mathrm{eV}$ correspond to metallic $\mathrm{Ti}^{0}$ in TiW. ${ }^{27,28}$ The area ratio of W/Ti corrected by photoionization cross-section is 2.4: the TiW substrate contains more W than Ti. In Figure 4a, O1s spectra shows two peaks located at 530.5 $\mathrm{eV}$ and $531.3 \mathrm{eV}$ which are identified as contributions from metal oxides (labelled Metal-O) and from metal hydroxides (labelled Metal-OH). A third peak is attributed to oxygen contamination. Contributions in $\mathrm{O} 1 \mathrm{~s}$ from bonding with $\mathrm{W}$ and $\mathrm{Ti}$ are too close to be separated, 
therefore, TiW will be referred as "metal" (M) in the following. ${ }^{29}$ As these results indicate that $\mathrm{OH}$ groups were present on the surface of the TiW substrate, the surface could be functionalized by organosilane, organophosphonic acid and ortho-dihydroxyaryl compounds.

The thickness of the oxidized TiW layer $\mathrm{t}_{\text {oxide }}$ can be estimated from Figure 3a. The intensity attenuation of $\mathrm{W}^{0} 4 \mathrm{f}$ by the oxidized TiW layer according to Beer Lambert law is: $\mathrm{A} \sim(1-\exp (-$ $\left.\left.\mathrm{t}_{\text {oxide }} / \lambda\right)\right) / \exp \left(-\mathrm{t}_{\text {oxide }} / \lambda\right)$, where $\mathrm{A}$ is the intensity area ratio $\mathrm{W}^{0} 4 \mathrm{f}_{7 / 2} / \mathrm{W}^{+6} 4 \mathrm{f}_{7 / 2}, \lambda$ is the mean free path of electrons in the oxide ( $\lambda$ for $\mathrm{W}^{0} 4 \mathrm{f} 7 / 2 \sim 3.8 \mathrm{~nm}$ from the predictive formulae, ${ }^{30} \mathrm{t}_{\text {oxide }}$ is the oxide thickness. The surface oxide has a thickness $\mathrm{t}_{\text {oxide }} \sim 1 \mathrm{~nm}$.

The $\mathrm{OH}$ surface concentration $(\mathrm{Cs})_{\mathrm{OH}}$ was estimated from XPS O1s core level, according to the method presented by Shircliff: ${ }^{31}$

$$
(C s)_{O H} \sim \frac{A(\text { metal }-O H)_{T i W}}{A(O 1 s)_{\text {TiW }}} n_{\text {oxide }} . t_{\text {oxide }}
$$

where $\mathrm{A}(\mathrm{Metal}-\mathrm{OH})_{\mathrm{TiW}}$ is the normalized area (corrected by photoionization cross-section) of the component (Metal-OH) in $\mathrm{O} 1 \mathrm{~s}$ and $\mathrm{A}(\mathrm{O} 1 \mathrm{~s})_{\mathrm{TiW}}$ is the total normalized area of $\mathrm{O} 1 \mathrm{~s}$ for bare oxidized TiW surface. The normalized areas for O1s components are reported in Table 2 . The molecular concentration $n_{\text {oxide }}$ of oxidized TiW was calculated by approximating oxidized TiW as a composition of $\mathrm{TiO}_{2}$ and $\mathrm{WO}_{3}$. Density d $\left(\mathrm{g} \cdot \mathrm{nm}^{-3}\right)$ and molar mass $\left(\mathrm{mol} . \mathrm{g}^{-1}\right)$ of $\mathrm{TiO}_{2}$ and $\mathrm{WO}_{3}$ were used to evaluate the molar concentration $\left(\mathrm{mol} . \mathrm{nm}^{-3}\right)$ of TiW oxide, taking into account the W:Ti ratio of 17.6/7.2 2.4 as measured by XPS. This yielded an approximated value of $n_{\text {oxide }} \sim 22$ molecules.nm ${ }^{-3}$. $t_{\text {oxide }}$ is the above evaluated oxidized TiW thickness $(\sim 1$ $\mathrm{nm})$. $\mathrm{A}($ metal-OH $)$ and $\mathrm{A}(\mathrm{O} 1 \mathrm{~s})$ are given in Table 2. The calculated $(\mathrm{Cs})_{\mathrm{OH}}$ value using this method is approximately $3 \mathrm{OH} \cdot \mathrm{nm}^{-2}$. This is close to the value reported for hydroxyl groups in the case of $\mathrm{TiO}_{2}$ substrates. ${ }^{32}$ XPS measurements are expected to overestimate surface concentrations because of surface roughness. 


\section{APDMES, APPA, and DA binding mode on oxidized TiW surface}

O1s core levels are shown in Figure 4. N1s, P2p, and Si2p core levels are shown on Figure 6. XPS survey spectra of APDMES-TiW, APPA-TiW and DA-TiW are shown on Figure S1. APPA-TiW shows distinct N1s (401.0 eV), P2s (190.3 eV), and P2p (133.2 eV) peaks, APDMES-TiW shows distinct N1s (401.0 eV), Si2s (153.3 eV) and Si2p (101.3 eV) peaks and DA-TiW shows distinct N1s $(401.0 \mathrm{eV})$ in addition to $\mathrm{W}$ and Ti core levels. The existence of N1s, P2p and/or Si2p confirms the success of the grafting. After surface functionalization, Ti, $\mathrm{W}$ and $\mathrm{O}$ atomic percentages decrease as expected for core levels from a substrate covered by an overlayer. The percentage ratio $\mathrm{W} 4 \mathrm{f} / \mathrm{Ti} 2 \mathrm{p}$ remains stable. As the percentage ratios $\mathrm{O} 1 \mathrm{~s} / \mathrm{Ti} 2 \mathrm{p}$ and $\mathrm{C} 1 \mathrm{~s} / \mathrm{Ti} 2 \mathrm{p}$ increase, part of the oxygen and/or carbon is thought to originate from the organic grafting.

On all functionalized surfaces, a similar $\mathrm{N}$ atomic percentage was observed (3-4\%). $3.3 \%$ of $\mathrm{P}$ and 3.6\% of Si were measured on APPA-TiW and APDMES-TiW, respectively. The N/P and $\mathrm{N} / \mathrm{Si}$ ratios (nearly 1) are in good agreement with the chemical structures of the two molecules.

\begin{tabular}{llllllll}
\hline & C1s & O1s & Ti2p & W4f & N1s & P2p & Si2p \\
\hline Control & $9.6 \pm 0.8$ & $65.6 \pm 1.1$ & $7.2 \pm 0.8$ & $17.6 \pm 0.8$ & - & - & - \\
& & & & & & & \\
\hline APPA-TiW & $33.3 \pm 1.0$ & $53.2 \pm 0.9$ & $2.0 \pm 0.6$ & $4.6 \pm 0.6$ & $3.6 \pm 0.3$ & $3.3 \pm 0.3$ & - \\
& & & & & & & $3.6 \pm 0.5$ \\
\hline APDMES-TiW & $29.8 \pm 0.9$ & $55.8 \pm 0.5$ & $2.4 \pm 0.7$ & $4.8 \pm 0.6$ & $3.5 \pm 0.4$ & - & \\
\hline DA-TiW & $38.7 \pm 0.5$ & $49.9 \pm 1.0$ & $2.7 \pm 0.5$ & $5.3 \pm 0.6$ & $3.3 \pm 0.3$ & - & -
\end{tabular}

Table 1. XPS atomic percentages of control and of three organolayers functionalized $\mathrm{O}_{2}$ plasma cleaned TiW. 


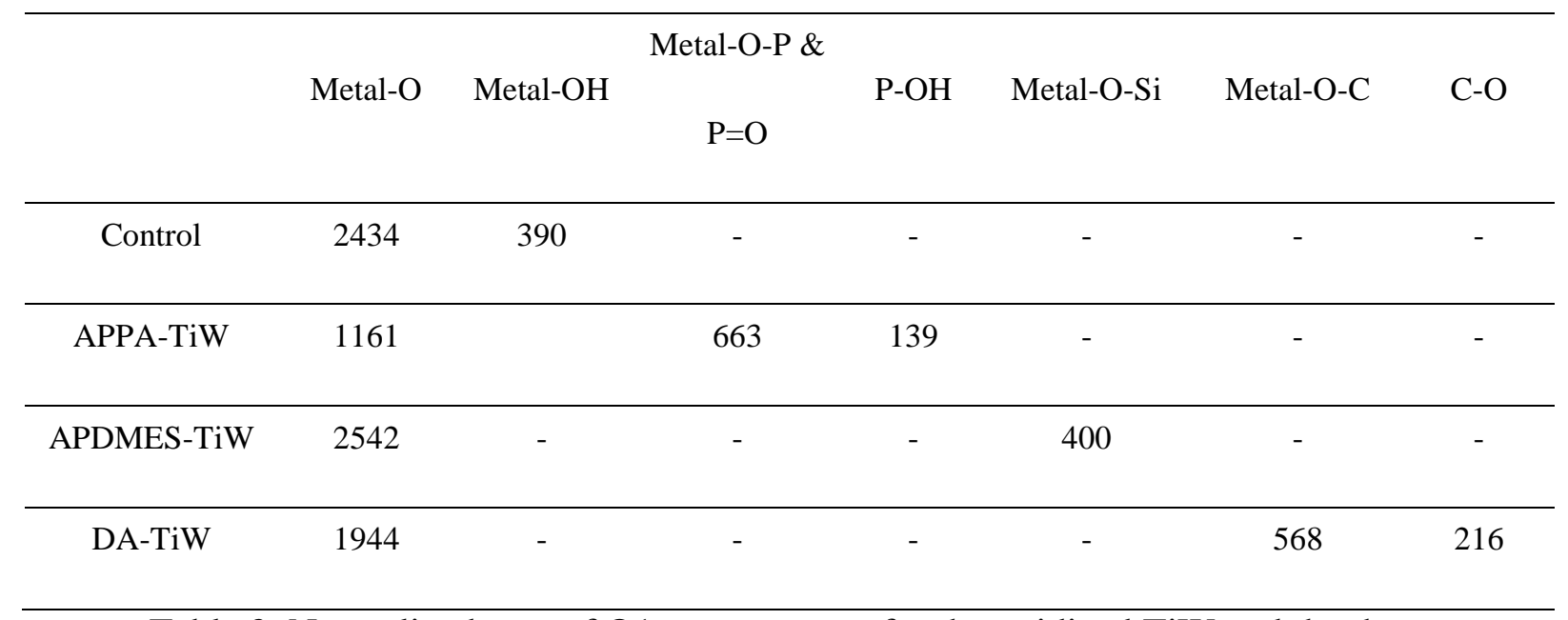

Table 2. Normalized area of O1s components for the oxidized TiW and the three organolayers on oxidized TiW.

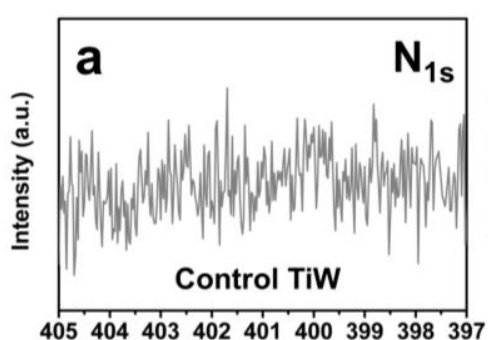
Binding energy $(\mathrm{eV})$

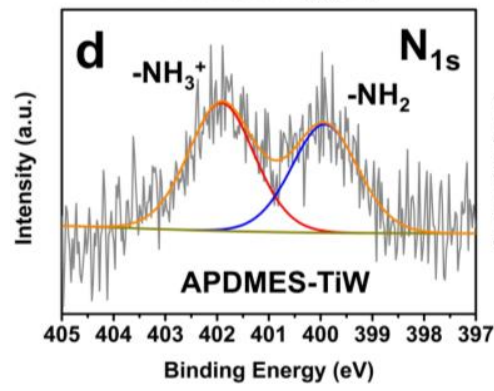

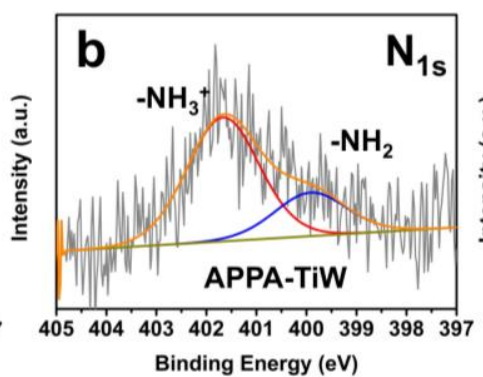
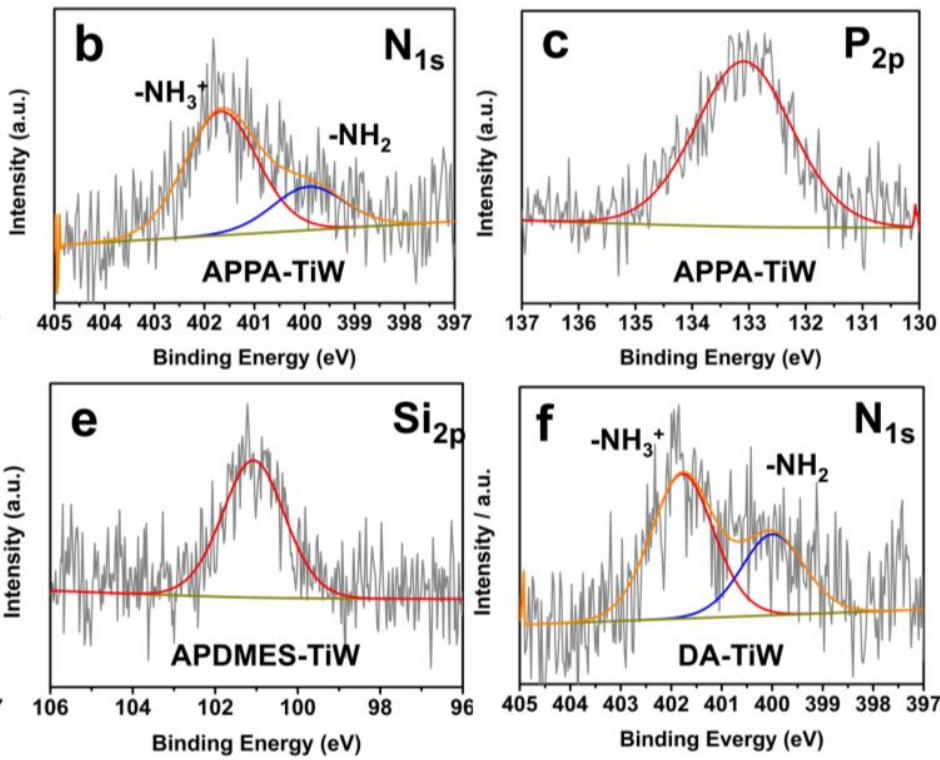

Figure 6. (a) N1s core level of control TiW. (b) N1s core level and (c) P2p core level of APPA-TiW, (d) N1s core level and (e) Si2p core level of APDMES-TiW, (f) N1s core level of DA-TiW.

Two contributions are present in the high-resolution N1s core level for APPA-TiW, APDMESTiW, and DA-TiW, which were associated with a free amine $-\mathrm{NH}_{2}$ group at $399.8 \mathrm{eV}$ and protonated amine $-\mathrm{NH}_{3}{ }^{+}$group at $401.7 \mathrm{eV}$, respectively. ${ }^{33,34}$ High-resolution XPS spectra of the P2p confirms phosphorus functionalization. In our work, after grafting on oxidized TiW, 
the $\mathrm{P} 2 \mathrm{p}$ is seen at $133.2 \mathrm{eV}$. The $\mathrm{P} 2 \mathrm{p}$ core level is expected at $134.1 \mathrm{eV}$ for the non-deprotonated $-\mathrm{PO}_{3} \mathrm{H}_{2}$ acid. ${ }^{35,36}$ It is generally accepted that a shift of $\mathrm{P} 2 \mathrm{p}$ toward lower binding energy is associated with the deprotonation of the terminal $\mathrm{P}-\mathrm{OH} \cdot{ }^{37-39}$ Therefore, the present shift to a lower binding energy seems to reveal a full or partial deprotonation of terminal P-OH groups. The P2p shift of $0.9 \mathrm{eV}$ observed here is in agreement with typical shifts reported for phosphonic acids on metal oxide surfaces. ${ }^{35,38}$ From high-resolution Si2p spectra of APDMESTiW (Figure 6e), a Si2p peak was observed at $101.3 \mathrm{eV}$ and assigned to the silicon $\mathrm{Si}-(\mathrm{O})_{1}$ of APDMES onto the oxidized TiW surface. ${ }^{40,41}$ The covalent attachment of a monofunctional organosilane is the result of a single condensation reaction to metal oxide surface. As the silicon atom of the organosilane is linked with a single oxygen atom, its binding energy must be lower than the one measured on silica or multifunctional silanes. ${ }^{33}$ The presence of APDMES is confirmed by the intense ATR-FTIR peak around $1260 \mathrm{~cm}^{-1}$ (Figure 5c), attributed to the Si$\mathrm{CH}_{3}$ bend. ${ }^{42}$ However the $\mathrm{NH}_{2}$ scissor vibration for APDMES at $1570 \mathrm{~cm}^{-1}$ was not observed in our case. It has been reported that the bonding between an amine and a surface bound hydroxyl is much weaker than any other bonding and rinsing with the solvent easily removes physisorbed molecules. ${ }^{18,43}$

The high-resolution O1s spectra of different organolayers coated on metal oxide surface have been reported on Figure 4. The binding energy of the components depends on the type of organolayers grafted on the surface. Figure 4a shows O1s core level of the initial oxidized TiW substrate. The Full width half maximum (FWHM) of the oxygen contribution was set to $1.4 \mathrm{eV} . \mathrm{O} 1 \mathrm{~s}$ is resolved into three contributions. The peak at $530.5 \mathrm{eV}$ is assigned to lattice oxygen from the metal oxides. The peak at $531.3 \mathrm{eV}$ was assigned to the chemisorbed oxygen caused by surface hydroxyl. The weak peak at $532.0 \mathrm{eV}$ represents the surface oxygen contamination. $^{44}$ 
For APPA-TiW, the ATR-FTIR spectrum absorbance peak around $1100 \mathrm{~cm}^{-1}$ in Figure 5 can be assigned to a convolution of symmetric and asymmetric stretching bands of the phosphonate groups $\left(\mathrm{PO}_{3}{ }^{2-}\right)$. The presence of this stretching vibration indicates the deprotonation of the phosphonic acid group. ${ }^{45,46} \mathrm{~A}$ broad band at $1250 \mathrm{~cm}^{-1}$ was assigned to the $\mathrm{P}=\mathrm{O}$ stretching mode from the free $\mathrm{P}=\mathrm{O}$ groups of molecules. It also indicated that APPA bonding to TiW surface occurred via deprotonated $\mathrm{OH}$ groups while the $\mathrm{P}=\mathrm{O}$ groups do not directly bond to the surface. This may correspond to modes (a1) monodentate APPA; (a2, a3) bridging bidentate APPA and (a4) chelating bidentate in Scheme 1. Other studies report that the bonding mode of phosphonate to the metal oxide surfaces occurs via a bidentate bonding (Figure 5b). ${ }^{47,48}$ APPA-TiW XPS analysis in Figure $4 \mathbf{b}$ provided further information: the peak at $531.6 \mathrm{eV}$ was assigned to $\mathrm{P}-\mathrm{O}-\mathrm{metal}$ and $\mathrm{P}=\mathrm{O}$. The contribution located at $532.8 \mathrm{eV}$ was ascribed to $\mathrm{P}-\mathrm{OH}$ species. The ratio of $\mathrm{P}=\mathrm{O}$ oxygen contribution over that of $\mathrm{P}-\mathrm{OH}$ should be 0.5 for pure APPA layer. By assuming that the sum of normalized area of the components (Metal-O-P, $\mathrm{P}=\mathrm{O}$ ) and $(\mathrm{P}-\mathrm{OH})$ in $\mathrm{O} 1 \mathrm{~s}$ is equal to 1.

The normalized area of the component (P-OH) is 0.17 (measurements reported on Table 2). Since one third of the bond between $\mathrm{P}$ and $\mathrm{O}$ of each APPA should be a $\mathrm{P}=\mathrm{O}$ in every mode in Scheme 1, the normalized area of the component $(\mathrm{P}=\mathrm{O})$ alone should be around 0.33 .

From these values, the normalized area of the component (Metal-O-P) was estimated around 0.5. If all bound APPA were only monodentate (binding mode a1), one third of the $(\mathrm{P}, \mathrm{O})$ bonds would correspond to (P-OH). However, XPS measurements show that P-OH accounts for only $17 \%$ of $(\mathrm{P}, \mathrm{O})$ bonds. Therefore, approximately half of APPA molecules are monodentate (one of the two P-OH is free, binding mode a1 in scheme 1), while the other half are bidendate (two Metal-O-P bonds per APPA molecule: binding modes a2, a3 or a4 in scheme1). 
XPS O1s core level was resolved into only two components (Figure 4c). Besides the Metal-O bonding oxygen, the peak at $531.7 \mathrm{eV}$ was attributed to oxygen atoms in surface hydroxyl or Si-O-metal species, which is in agreement with the other studies. ${ }^{49,50}$

For DA-TiW, XPS peak at 531.6 eV in Figure 4d was assigned to Metal-O-C. The peak located at higher binding energy $(533.0 \mathrm{eV})$ was ascribed to oxygen bonded to aromatic carbon. ${ }^{22,51}$ Although bidentate mode of attachment was referred to as the stable structure, we think that monodentate and bidentate complexes co-exist on the surface because of the peak at $533.0 \mathrm{eV}$

which means that only one of catechol $-\mathrm{OH}$ moiety is involved in the bonding. ${ }^{52}$ By assuming that the sum of normalized area of the components (Metal-O-C) and (C-O) in O1s is equal to 1, the normalized area of the component (C-O) is 0.27 (measurements reported in Table 2). From these values, the normalized area of the component (Metal-O-C) is estimated around 0.73. Approximately half of DA molecules would be monodentate (one of the two C-O is free), while the other half are bidendate (two Metal-O-C bonds per molecule).

\section{XPS Metal-O-P and Metal-O-Si components as a measurement of APPA \& APDMES surface coverages.}

XPS analysis was used for evaluating organolayer surface concentrations (Cs) for APPA and APDMES. These (Cs) values could be compared with theoretical values of the maximum surface concentration obtained for a compact monolayer $\left(\mathrm{Cs}_{\max }\right)$.

(Cs) surface concentration measured from XPS: we define herein experimental surface concentration as the number of organic molecules per area unit. (Cs) values were evaluated using two calculation methods: (a) contribution of N1s for each type organolayer, using nitrogen as a reporter for our organic molecules; (b) respective contributions of Si2p and P2p for APDMES-TiW and for APPA-TiW. The detected carbon contamination prevented us to use this second approach with C1s for DA-TiW. 
Calculations and XPS data are presented in equations 2 to 6 and Table 3 below:

$$
\begin{aligned}
& (C S)_{A P D M E S} \sim \frac{A(N 1 s)_{A P D M E S}}{A(\text { Metal-O })_{A P D M E S}} n_{\text {oxide }} t_{\text {oxide }} \\
& (C S)_{A P D M E S} \sim \frac{A(\text { Si2p })_{A P D M E S}}{A(\text { Metal }-O)_{A P D M E S}} n_{\text {oxide }} t_{\text {oxide }} \\
& (C s)_{A P P A}=\frac{A(N 1 s)_{A P P A}}{A(\text { Metal }-O)_{A P P A}} n_{\text {oxide }} t_{\text {oxide }} \\
& (C s)_{A P P A}=\frac{A(P 2 p)_{A P P A}}{A(\text { Metal }-O)_{A P P A}} n_{\text {oxide }} t_{\text {oxide }} \\
& (C S)_{D A}=\frac{A(N 1 s)_{D A}}{A(\text { Metal }-O)_{D A}} n_{\text {oxide }} t_{\text {oxide }}
\end{aligned}
$$

\begin{tabular}{|c|c|c|}
\hline $\begin{array}{l}\text { Organolayer on } \\
\text { oxidized TiW }\end{array}$ & $\begin{array}{l}\text { (Cs) surface concentration } \\
\left(\text { molecules.nm }{ }^{-2}\right)\end{array}$ & $\begin{array}{l}\left(\mathrm{Cs}_{\max }\right) \text { theoretical } \\
\text { maximum surface } \\
\text { concentration } \\
\left(\text { molecules.nm }{ }^{-2}\right)\end{array}$ \\
\hline Bare oxidized TiW & Using O1s: $~ 3$ OH.nm ${ }^{-2}$ & - \\
\hline APPA & $\begin{array}{l}\text { using N1s: } \sim 1.9 \pm 0.5 \text { APPA.nm }{ }^{-2} \\
\text { using P2p: } \sim 2.2 \pm 0.5 \text { APPA.nm }{ }^{-2}\end{array}$ & $4.7 \pm 0.9$ APPA.nm ${ }^{-2}$ \\
\hline APDMES & $\begin{array}{l}\text { using N1s: } 2.3 \pm 0.5 \text { APDMES.nm }{ }^{-2} \\
\text { using Si2p: } \sim 1.8 \pm 0.5 \text { APDMES.nm }{ }^{-2}\end{array}$ & $2.7 \pm 0.9$ APDMES.nm ${ }^{-2}$ \\
\hline DA & $\begin{array}{c}\text { using N1s: } \sim 1.6 \pm 0.5 \text { DA.nm }{ }^{-2} \\
\text { using C1s: not determined }\end{array}$ & $4.4 \pm 0.9$ DA.nm ${ }^{-2}$ \\
\hline
\end{tabular}

\begin{tabular}{cccc}
\hline Organolayer & N1s & P2p & Si2p \\
\hline APPA-TiW & 121.5 & 132.5 & - \\
\hline APDMES-TiW & 220.9 & - & 199.1 \\
\hline DA-TiW & 145.9 & - & -
\end{tabular}

Table 3: Normalized area of N1s, P2p and Si2p for the three organolayers on oxidized TiW Results are presented in Table 4. 
Table 4. evaluation of surface concentrations. (Cs) surface concentration of $-\mathrm{OH}$ moieties on bare oxidized TiW, and surface concentration of bound molecules estimated from XPS measurements; for each organolayer, calculations were performed using XPS data for N1s. Additionally XPS data of P2p and Si2p were also used for APPA and Si, respectively. XPS data of $\mathrm{C} 1 \mathrm{~s}$ could not be used for DA because of atmospheric carbon contamination. $(\mathrm{Cs})_{\max }$ theoretical maximum surface density calculated for compact organolayer and estimated from theoretical calculations after Shircliff et al. ${ }^{31}$

The calculated values in for N1s, Si2p and P2p seem consistent. ToF-SIMS considerations enabled to confirm XPS results (see below). DA surface concentration could not be determined because of difficult interpretation in spectra related to carbon contamination.

\section{(Csmax) theoretical maximum surface concentration calculated for saturated monolayers:} theoretical maximum surface concentration calculated for saturated monolayers of APDMES, APPA and DA were calculated using the method presented by Shircliff et al. ${ }^{31}$ given in equation (7):

$$
\left(C s_{\max }\right)=\frac{\text { t.d.a.N }}{M W}
$$

Where $t$ is the monolayer thickness $(0.6+/-0.2 \mathrm{~nm}), d$ is the density of APDMES, APPA and DA $\left(0.857 \mathrm{~g} / \mathrm{cm}^{3} ; 1.378 \mathrm{~g} / \mathrm{cm}^{3} ; 1.47 \mathrm{~g} / \mathrm{cm}^{3}\right.$ respectively $), a$ is a conversion factor $\left(10^{-21}\right.$ $\left.\mathrm{cm}^{3} / \mathrm{nm}^{3}\right), N$ is Avogadro's number, and $M W$ is the molecular weight of APDMES, APPA and DA without their hydrolysable moieties (116 g/mol, $105 \mathrm{~g} / \mathrm{mol}$ and $122 \mathrm{~g} / \mathrm{mol}$, respectively) . The calculations result in 2.7 +/- 0.9 APDMES molecules.nm ${ }^{-2}, 4.7$ +/- 0.9 APPA molecules.nm ${ }^{-2}$, and $4.4+/-0.9$ DA molecules.nm ${ }^{-2}$. These values are higher than the experimental surface concentration (Cs) calculated from our XPS measurements. It therefore suggests that our three organolayers are not compact. 
ToF-SIMS analysis was also used to characterize the three organolayers functionalized TiW with the aim of confirming XPS results thanks to the molecular information brought by the mass detection. Due to contamination issues -to which ToF-SIMS is by far more sensitive than XPS- fresh samples were prepared just prior to ToF-SIMS analysis, in order to limit atmospheric contamination as much as possible.
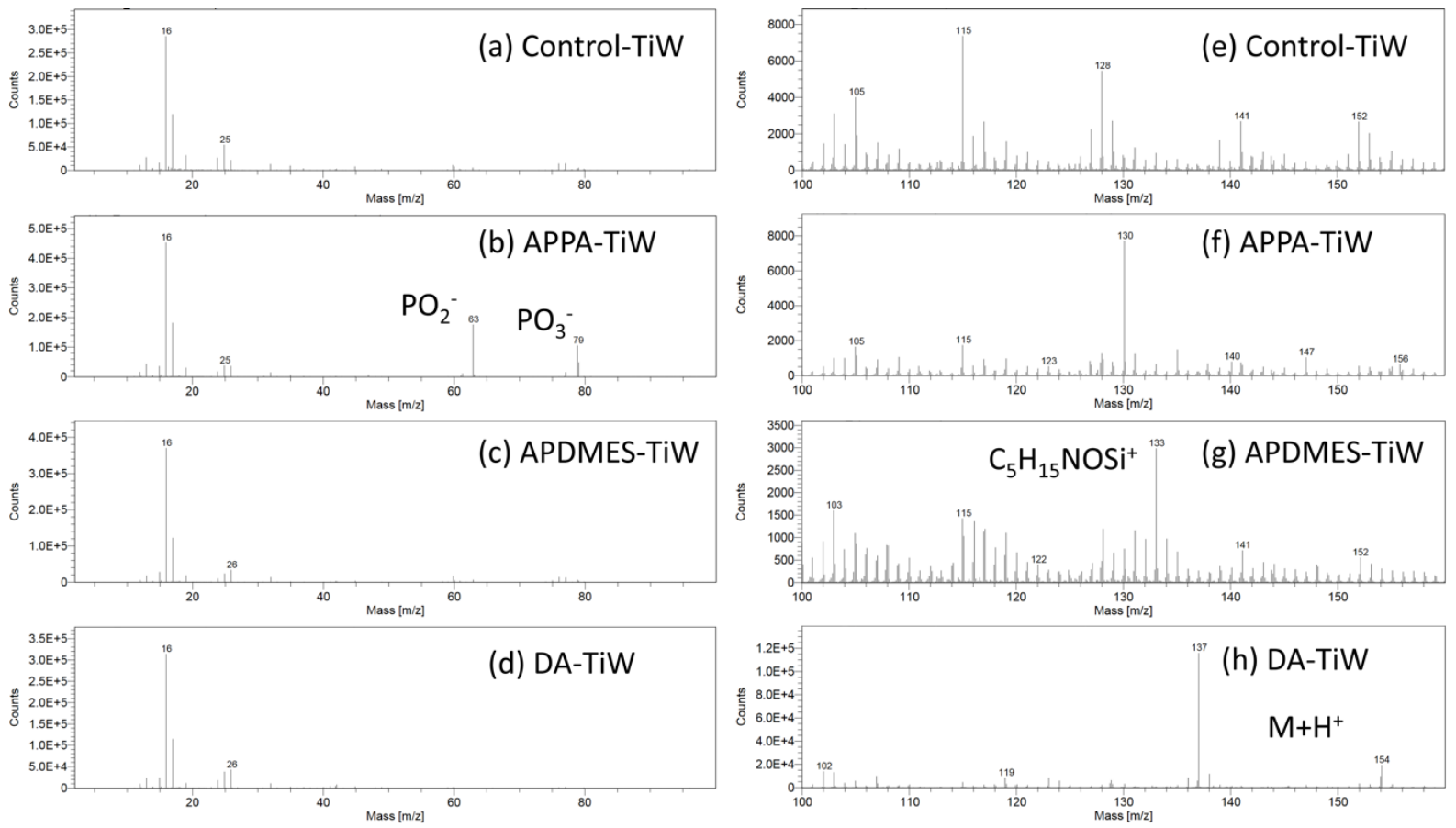

Figure 7. Negative mode (a-d) and positive mode (e-h) ToF-SIMS spectra of control TiW, APPA-TiW, APDMES-TiW and DA-TiW in the ranges of $\mathrm{m} / \mathrm{z}=0-100$ (negative mode) and $\mathrm{m} / \mathrm{z}=100-160$ (positive mode).

Negative mode spectra (Figure 7a-d) firstly indicates an increase in relative intensity of the nitrogen containing ions for APPA, APDMES and DA modified TiW compared to control bare TiW treated with $\mathrm{O}_{2}$ plasma. For example, on the bare $\mathrm{TiW}$, the main contribution at $\mathrm{m} / \mathrm{z}=26$ is assigned to $\mathrm{C}_{2} \mathrm{H}_{2}{ }^{-}$at $\mathrm{m} / \mathrm{z}=26.02$ ion, while on the organolayers the main contribution is the $\mathrm{CN}^{-}$peak detected at $\mathrm{m} / \mathrm{z}=26.00$. A strong relative intensity for the phosphonic acid group characteristic peaks $\left(\mathrm{PO}_{2}{ }^{-} \mathrm{m} / \mathrm{z} 62.97\right.$ and $\mathrm{PO}_{3}{ }^{-} \mathrm{m} / \mathrm{z}$ 78.97) is specifically detected for the APPATiW. ${ }^{61}$ An increase in the relative intensity of the peak at $\mathrm{m} / \mathrm{z} 30\left(\mathrm{CH}_{4} \mathrm{~N}^{+}\right)$is noticeable after surface formation of the organolayers. Contamination is also detected such as aromatic peaks 
at $\mathrm{m} / \mathrm{z} 77.04,91.05,105.07,115.05$ etc. corresponding to $\mathrm{C}_{6} \mathrm{H}_{5}{ }^{+}, \mathrm{C}_{7} \mathrm{H}_{7}{ }^{+}, \mathrm{C}_{8} \mathrm{H}_{9}{ }^{+}, \mathrm{C}_{9} \mathrm{H}_{7}{ }^{+}$, respectively (Figure 7e-h). Nitrogen-based contamination has been also detected at the surface of the APPA-TiW sample at m/z 130.15. APDMES and DA molecular information related to the functionalization was more clearly detected in the positive mode. For APDMES-TiW samples, peaks were detected at $\mathrm{m} / \mathrm{z}=116.09\left(\mathrm{C}_{5} \mathrm{H}_{14} \mathrm{NSi}^{+}\right)$and $133.08\left(\mathrm{C}_{5} \mathrm{H}_{15} \mathrm{NOSi}^{+}\right)$. For DATiW samples, a peak is detected at $\mathrm{m} / \mathrm{z}=154.08$ that corresponds to $\mathrm{M}+\mathrm{H}^{+}$. A peak was also detected in the negative mode at $\mathrm{m} / \mathrm{z}=152.06$, corresponding to $\mathrm{M}-\mathrm{H}^{-}$(data not displayed). In positive mode spectra (Figure S2), strong relative intensities of peaks related to Ti such as peaks at $\mathrm{m} / \mathrm{z} 47.95$ and m/z 63.94 for $\mathrm{Ti}^{+}$and $\mathrm{TiO}^{+}$are observed. Similarly, W related peaks (data not displayed) were also observed. ToF-SIMS is sensitive to the top layers (one to a few monolayers) and is thus more sensitive to the top surface than XPS for which the information depth corresponds to $3-10 \mathrm{~nm}$. As the TiW substrate is still significantly detected, this indicates that it is not fully covered with the intended surface modification. This is consistent with our discussion about XPS. Considering the results and discussions in parts 3.2 and 3.3, we considered that all initial metal-OH of oxidized TiW were used for binding organolayers. However, the final organolayer surface concentrations indicate the formations of submonolayers. In further work, increasing the initial density of metal-OH moieties may be a way to increase the compactness of implemented organolayers.

\section{Effects of immersion in DI water at $70^{\circ} \mathrm{C}$}

Lereau et al. demonstrated that the half-life of monothiol organolayers on gold was less than 5

minutes in hot water. ${ }^{53}$ Inspired by this report we choose to compare the stability of the three organolayers by immersion of the modified $\mathrm{TiW}$ in $70^{\circ} \mathrm{C}$ water. XPS atomic percentages were determined as a function of immersion time. The change of different elements concentration is listed in Table 5. 


\begin{tabular}{cccccccc}
\hline & C1s & O1s & Ti2p & W4f & N1s & P2p & Si2p \\
\hline APPA-TiW & $30.6 \pm 0.7$ & $57.5 \pm 0.6$ & $2.5 \pm 0.4$ & $4.5 \pm 0.5$ & $2.5 \pm 0.2$ & $2.4 \pm 0.3$ & - \\
\hline APDMES-TiW & $22.7 \pm 0.6$ & $61.1 \pm 0.5$ & $5.0 \pm 0.6$ & $10.5 \pm 0.7$ & $0.3 \pm 0.1$ & - & $0.4 \pm 0.1$ \\
\hline DA-TiW & $29.2 \pm 0.8$ & $58.8 \pm 0.9$ & $2.8 \pm 0.5$ & $7.6 \pm 0.4$ & $1.6 \pm 0.2$ & - & -
\end{tabular}

Table 5: XPS atomic percentages of the APPA-TiW, APDMES-TiW and DA-TiW after 60 minutes immersion in $70^{\circ} \mathrm{C}$ DI water. To be compared with Table 2.

The ratios of N1s at. $\%$ to (Ti2p at. $\%+\mathrm{W} 4 \mathrm{f}$ at. $\%$ ) as a function of time are displayed in Figure 8a. The N1s at. \% / (Ti2p at. \%+W4f at. \%) ratio of APPA-TiW decreased from 0.55 to 0.38 within the first 15 minutes and then, it remained constant for the next 45 minutes. In a similar fashion (Figure 8b), the P2p at. \% / (Ti2p at. \%+W4f at. \%) ratio decreases and reaches a plateau after 15 minutes of immersion time. For DA-TiW, the N1s at. \% / (Ti2p at. \%+W4f at. $\%$ ) ratio decreased continuously from 0.42 to 0.19 after 60 minutes of immersion time. Finally, for APDMES, the N1s at. \% / (Ti2p at. \%+W4f at. \%) ratio drops to 0 within 15 minutes. In a similar manner (APDMES-TiW), the Si2p at. \% / (Ti2p at. \% +W4f at. \%) ratio decreases with increased immersion time and $\mathrm{Si}$ is not significantly observed after 15-30 minutes of immersion time (Figure 8c). On the contrary, the contributions of the substrate increase from 2.5 to $5 \%$ after $60 \mathrm{~min}$ immersion for Ti2p at. $\%$ and from 5 to $10 \% \mathrm{f}$ after $60 \mathrm{~min}$ immersion or $\mathrm{W} 4 \mathrm{f}$ at. $\%$ illustrating the removal of the APDMES organolayers (Table 4). Therefore, it is estimated that the APDMES layer is almost fully removed. $50 \%$ of the DA layer and nearly $30 \%$ of the APPA layer are depleted after 60 minutes of immersion (Figure 8d). Our results suggest that the rate and amount of molecules desorbed for APDMES-TiW is the highest. DA-TiW seems slightly less stable than APPA-TiW. 
In some comparative published studies, the stability of different organolayers on metal oxide have been reported. ${ }^{44,54-62}$ The exact state of bonding responsible for the stability of organolayers on metal oxides is still a matter of debate. It has been claimed that Si-O-Ti is more stable than P-O-Ti. ${ }^{44,54}$ However, M. J. Stevens suggested that the stability was rather in fact due to the lateral crosslinking of multifunctional organosilane. ${ }^{55}$ In our case, lateral cross linking was not possible as we have used a monovalent silane. We observed that the APDMES layer was almost completely removed after 15 min of immersion time in $70{ }^{\circ} \mathrm{C} \mathrm{H}_{2} \mathrm{O}$ suggesting that the $\mathrm{Si}-\mathrm{O}-\mathrm{Ti}$ or $\mathrm{Si}-\mathrm{O}-\mathrm{W}$ bonds are somehow labile and that the stability reported by several authors may rather be due to lateral cross linking. Different phosphonate layers on indium-tin oxide, cobalt chromium alloys and aluminum surfaces were found to be stable and strongly bound. ${ }^{56-61}$ In addition, it has been showed that tungsten oxide surface can react with phosphonate molecules to form the covalently attach tethered by phosphonate linkers. And the $\mathrm{P}-\mathrm{O}$ bonds $(3.5 \mathrm{eV} / \mathrm{bond})$ on tungsten/tungsten oxide seems to be twice as strong as $\mathrm{S}-\mathrm{Au}$ attachments $(1.7 \mathrm{eV} / \mathrm{bond}) .{ }^{62}$ Here the rate and amount of molecules desorbed for APPA-TiW are lower compared to the other two layers which maybe resulted from the stronger P-O-Ti and P-O-W covalent bonds. For DA layer, we proposed that monodentate and bidentate complexes of catechol co-exist on the surface. In the literature, the bidentate attachment is considered more stable than the monodendate complex. ${ }^{4}$ It may well be that after immersion in $70{ }^{\circ} \mathrm{C}_{2} \mathrm{O}$, the relatively unstable monodentate complexes may continuously desorb from the surface. ${ }^{45}$, 51,63 

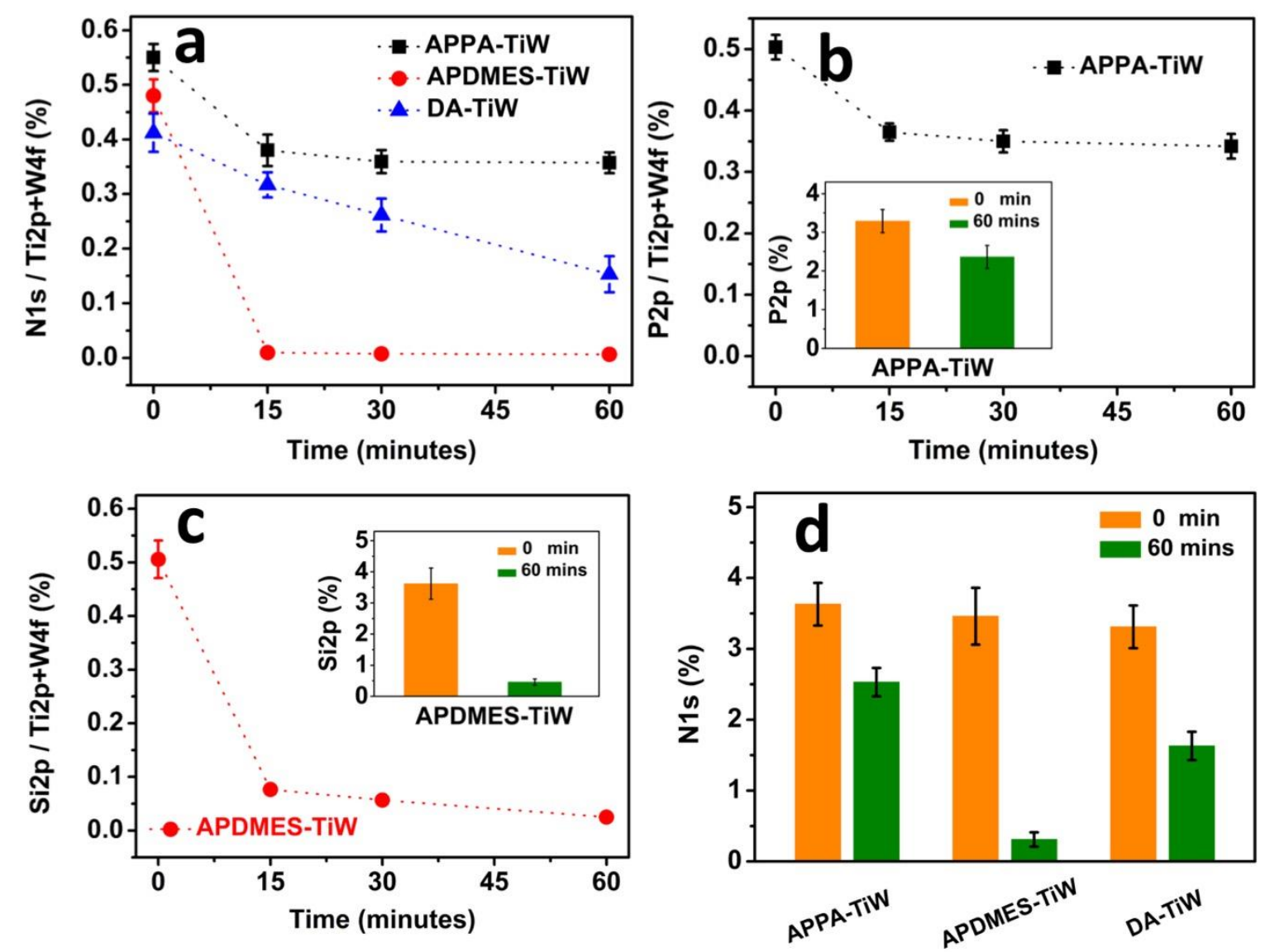

Figure 8. (a) N1s at. $\% /($ Ti2p at. $\%+\mathrm{W} 4 \mathrm{f}$ at. $\%$ ) ratio for the APPA- TiW, APDMES-TiW and DA-TiW as a function of immersion time in DI water at $70^{\circ} \mathrm{C}$. (b) P2p at. \% / (Ti2p at. \% $+\mathrm{W} 4 \mathrm{f}$ at. \%) ratio of APPA-TiW DI $\mathrm{H}_{2} \mathrm{O}$ at $70^{\circ} \mathrm{C}$ as a function of immersion time. The inset shows the P2p concentration change. (c) Si2p at. \% / (Ti2p at. \% +W4f at. \%) ratio of APDMES-TiW in DI $\mathrm{H}_{2} \mathrm{O}$ at $70^{\circ} \mathrm{C}$ as a function of immersion time. The inset shows the $\mathrm{Si} 2 \mathrm{p}$ concentration change. (d) N1s atomic percentage (at. \%) of APPA-TiW, APDMES-TiW and DA-TiW before and after 60 minutes' immersion in $\mathrm{DI}_{2} \mathrm{O}$ at $70^{\circ} \mathrm{C}$.

\section{CONCLUSION}

Herein we have studied the grafting of phosphonate, silane and ortho-dihydroxyaryl compounds on oxygen plasma cleaned TiW. The resulting layers were analyzed by XPS, ToFSIMS and IR. Firstly, XPS, IR and ToF-SIMS spectroscopy seem to sustain the formation of a covalent attachment between APPA and TiW. Similarly, the bonding of the APDMES layer seems to occur through the covalent bonds between the monovalent silane and oxide. Our 
results tend to indicate that DA binding on TiW leads to monodentate and bidentate configurations grafting. The stabilities of three organolayers on TiW was also investigated and compared. Based on XPS, the good stability of APPA organolayer may mainly be attributed to stronger P-O-W and P-O-Ti covalent bonds. The stability of DA organolayer on TiW was inferior to the stability of APPA organolayer probably because of the instability of monodentate mode. Extensive desorption of APDMES molecules occurred within 15 min of immersion in $70{ }^{\circ} \mathrm{C}$ water due to the lack of lateral cross linking in the layer. As a novel functional metal oxide, quite good stability of phosphonic acid organolayer functionalized TiW has important significance in terms of further functionalization and integrated multi-materials patterned substrate devices ${ }^{64,65}$.

This study sets the basis of TiW functionalization for our future work on the development of chemical sensors and biosensors based on industrial nanoelectronic devices. Futher work may indeed be performed for grafting biomolecular probes onto TiW. Biomolecules may for instance be immobilized using a cross-linker exhibiting at one end a phosphonate moiety, and at the other end a reactive group such as carboxylic acid ${ }^{65}$. Biomolecules such as proteins, peptide nucleic acids or oligonucleotides bearing a terminal primary amine could then be grafted on such surface, prior to assessing the nanoelectronic sensors.

\section{ASSOCIATED CONTENT}

Supporting Information. The Supporting Information is available free of charge on the ACS Publications website at DOI:

XPS survey scans; Positive mode ToF-SIMS spectra of control TiW, APPA-TiW, APDMESTiW and DA-TiW in the ranges of $\mathrm{m} / \mathrm{z}=20-160$; (PDF)

\section{AUTHOR INFORMATION}




\section{Corresponding Authors}

Dr. Yann Chevolot Tel.: +33 (0) 4721860 58. E-mail: yann.chevolot@ec-lyon.fr

Prof. Jean-Pierre Cloarec Tel.: +33 (0) 4721862 52. E-mail: jean-pierre.cloarec@ec-lyon.fr

\section{ORCID}

Yann Chevolot: 0000-0003-3479-3371

Jean-Pierre Cloarec: 0000-0002-4058-6697

\section{Author Contributions}

The manuscript was written through contributions of all authors. All authors have given approval to the final version of the manuscript.

\section{Notes}

The authors declare no competing financial interest.

\section{ACKNOWLEDGMENTS}

China Scholarship Council is grateful to offer Ph.D. fellowship to J. Z. Thanks are given to NanoLyon platform for technical support.

\section{REFERENCES}

(1) Zhou, X.; Boey, F.; Huo, F.; Huang, L.; Zhang, H. Chemically functionalized surface patterning. Small 2011, 7, 2273-2289.

(2) Liang, Y.; Kiick, K. L. Heparin-functionalized polymeric biomaterials in tissue engineering and drug delivery applications. Acta Biomaterialia 2014, 10, 1588-1600.

(3) Liu, J.; Lu, Y. Adenosine-Dependent Assembly of aptazyme-functionalized gold Nanoparticles and its application as a colorimetric biosensor. Anal. Chem. 2004, 76, 16271632. 
(4) Jerman, I.; Vuk, A. Š.; Koželj, M.; Orel, B.; Kovač, J. A structural and corrosion study of triethoxysilyl functionalized POSS coatings on AA 2024 alloy. Langmuir 2008, 24, 50295037.

(5) Rahhal, L., Ayele, G. T., Monfray, S., Cloarec, J. P., Fornacciari, B., Pardoux, E., ... \& Garnier, P. (2017). High sensitivity pH sensing on the BEOL of industrial FDSOI transistors. Solid-State Electronics 2017, 134, 22-29.

(6) Ayele, G. T., Monfray, S., Ecoffey, S., Boeuf, F., Cloarec, J. P., Drouin, D., \& Souifi, A. (2018). Ultrahigh-Sensitive CMOS pH Sensor Developed in the BEOL of Standard $28 \mathrm{~nm}$ UTBB FDSOI. IEEE Journal of the Electron Devices Society 2018, 6, 1026-1032.

(7) Wang, C. K.; Changa, S. J.; Su, Y. K.; Chang, C. S.; Chiou, Y. Z.; Kuo, C. H.; Lin, T. K.; Ko, T. K.; Tang, J. J. GaN MSM photodetectors with TiW transparent electrodes. Materials Science \& Engineering B 2004, 112, 25-29.

(8) Chiu, H. C.; Chen, C. H.; Yang, C. W.; Kao, H. L.; Huang, F. H.; Peng, S. W. Highly thermally stable in situ $\mathrm{SiN}_{\mathrm{X}}$ passivation $\mathrm{AlGaN} / \mathrm{GaN}$ enhancement-mode high electron mobility transistors using TiW refractory gate structure. J. Vac. Sci. Technol. B. 2013, 31, 051212.

(9) Roshanghias, A.; Khatibi, G.; Pelzer, R.; Steinbrenner, J. On the effects of thickness on adhesion of TiW diffusion barrier coatings in silicon integrated circuits. Surf. Coat. Technol. 2014, 259, 386-392.

(10) Battegay, F.; Fourel, M. Barrier material selection for TSV last, flipchip \& 3D-UBM \& RDL integrations. ECTC 2015, 1183-1192. 
(11) Bhagat, S. K.; Theodore, N. D.; Alford. T. L. Thermal stability of tungsten-titanium diffusion barriers for silver metallization. Thin Solid Films 2008, 516, 7451-7457.

(12) Alay, J. L.; Bender, H.; Brijs, G.; Demesmaeker, A.; Vandervorst. W. Quantitative analysis of $\mathrm{W}(\mathrm{N})$, TiW and TiW(N) matrices using XPS, AES, RBS, EPMA and XRD. Surf Interface Anal. 1991, 17, 373-382.

(13) Wang, S.; Suthar, S.; Hoeflich, C.; Burrow. B. Diffusion barrier properties of TiW between Si and Cu. J. Appl. Phys. 1993, 73, 2301-2320.

(14) Chiou, J. C.; Chen. M. C. Thermal stability of $\mathrm{Cu} / \mathrm{CoSi} 2$ contacted $\mathrm{p}^{+} \mathrm{n}$ shallow junction with and without TiW diffusion barrier. J. Electrochem. Soc. 1994, 141, 2804-2810.

(15) Chiou, J. C.; K. C. Juang, M. C. Chen. TiW (N) as diffusion barriers between Cu and Si. J. Electrochem. Soc. 1995, 142, 2326-2331.

(16) Li, F. H.; Fabbri, J. D.; Yurchenko, R. I.; Mileshkin, A. N.; Hohman, J. N.; Yan, H.; Yuan, H.; Tran, I. C.; Willey, T. M.; Bagge-Hansen, M.; Dahl, J. E. P.; Carlson, R. M. K.; Fokin, A. A.; Schreiner, P. R.; Shen, Z.; Melosh, N. A. Covalent attachment of diamondoid phosphonic acid dichlorides to tungsten oxide surfaces. Langmuir 2013, 29, 9790-9797.

(17) Bishop, L. M.; Yeager, J. C.; Chen, X.; Wheeler, J. N.; Torelli, M. D.; Benson, M. C.; Burke, S. D.; Pedersen, J. A.; Hamers. R. J. A citric acid-derived ligand for modular functionalization of metal oxide surfaces via 'click' chemistry. Langmuir 2012, 28, 1322-1329.

(18) Pujari, S. P.; Scheres, L.; Marcelis, A. T. M.; Zuilhof, H. Covalent surface modification of oxide surfaces. Angew. Chem. Int. Ed. 2014, 53, 6322-6356. 
(19) Brodard-Severac, F.; Guerrero, G.; Maquet, J.; Florian, P.; Gervais, C.; \& Mutin, P. H. High-field 17O MAS NMR investigation of phosphonic acid monolayers on titania. Chemistry of Materials 2008, 20(16), 5191-5196.

(20) Zhang, B.; Kong, T.; Xu, W.; Su, R.; Gao, Y.; \& Cheng, G. (2010). Surface functionalization of zinc oxide by carboxyalkylphosphonic acid self-assembled monolayers. Langmuir 2010, 26, 6, 4514-4522.

(21) Palazon, F.; Léonard, D.; Le Mogne, T.; Zuttion, F.; Chevalier, C.; Phaner-Goutorbe, M.;Souteyrand, E.; Chevolot, Y. \& Cloarec, J. P. Orthogonal chemical functionalization of patterned gold on silica surfaces. Beilstein J. Nanotechnol. 2015 6, 1, 2272-2277.

(22) Rodenstein, M.; Zürcher, S.; Tosatti, S. G. \& Spencer, N. D. Fabricating chemical gradients on oxide surfaces by means of fluorinated, catechol-based, self-assembled monolayers. Langmuir 2010, 26, 21, 16211-16220.

(23) Aissaoui, N.; Bergaoui, L.; Landoulsi, J.; Lambert, J. F. \& Boujday, S. Silane layers on silicon surfaces: mechanism of interaction, stability, and influence on protein adsorption. Langmuir 2011, 28, 1, 656-665

(24) Maxisch, M.; Ebbert, C.; Torun, B.; Fink, N.; De Los Arcos; T., Lackmann, J.; Maier, H.J. \& Grundmeier, G. PM-IRRAS studies of the adsorption and stability of organophosphonate monolayers on passivated NiTi surfaces. Appl. Surf. Sci. 2011, 257, 6, 2001-2018.

(25) Xu, S.; Diao, L. Study of tungsten oxidation in $\mathrm{O}_{2} / \mathrm{H}_{2} / \mathrm{N}_{2}$ downstream plasma. J. Vac. Sci. Technol. A. 2008, 26, 360-364. 
(26) Xie, F. Y.; Gong, L.; Liu, X.; Tao, Y. T.; Zhang, W. H.; Chen, S.H.; Meng, H.; Chen, J. XPS studies on surface reduction of tungsten oxide nanowire film by $\mathrm{Ar}^{+}$bombardment. Journal of Electron Spectroscopy and Related Phenomena 2012, 185, 112-118.

(27) Vogel, U.; Brachmann, E.; Oswald, S.; Menzel, S.; Gemming, T.; Eckert, J. Evaluation of a mobile vacuum transfer system for in vacuo XPS analysis using as-deposited Ti thin-films. Vacuum 2015, 117, 81-84.

(28) Riboni, F.; Bettini, L. G.; Bahnemann, D. W.; Selli, E. $\mathrm{WO}_{3}-\mathrm{TiO}_{2}$ vs. $\mathrm{TiO}_{2}$ photocatalysts: effect of the $\mathrm{W}$ precursor and amount on the photocatalytic activity of mixed oxides. Catalysis Today 2013, 209, 28-34.

(29) Lewera, A.; Timperman, L.; Roguska, A.; Alonso-Vante, N. Metal-support interactions between nanosized $\mathrm{Pt}$ and metal oxides $\left(\mathrm{WO}_{3}\right.$ and $\left.\mathrm{TiO}_{2}\right)$ studied using $\mathrm{X}$-ray photoelectron spectroscopy. J. Phys. Chem. C 2011, 115, 20153-20159.

(30) Tanuma, S.; Powell, C. J. \& Penn, D. R. (1993). Calculations of electron inelastic mean free paths (IMFPS). IV. Evaluation of calculated IMFPs and of the predictive IMFP formula TPP-2 for electron energies between 50 and 2000 eV. Surf. Interface Anal. 1993 20, 1, 77-89.

(31) Shircliff, R. A.; Martin, I. T.; Pankow, J. W.; Fennell, J.; Stradins, P.; Ghirardi, M. L.; Cowley, S. W.; Branz, H. M. High-resolution X-ray photoelectron spectroscopy of mixed silane monolayers for DNA attachment. ACS Appl. Mater. Interfaces 2011, 3, 3285-3292.

(32) Mueller, R.; Kammler, H. K.; Wegner, K.; Pratsinis, S. E. OH Surface Density of $\mathrm{SiO}_{2}$ and $\mathrm{TiO}_{2}$ by thermogravimetric analysis. Langmuir 2003, 19, 160-165.

(33) Yang, Z.; Chevolot, Y.; Géhin, T.; Dugas, V.; Xanthopoulos, N.; Laporte, V.; Delair, Y.; Ataman-Önal, Y.; Choquet-Kastylevsky, G.; Souteyrand, E.; Laurenceau, E. Characterization 
of three amino-functionalized surfaces and evaluation of antibody immobilization for the multiplex detection of tumor markers involved in colorectal cancer. Langmuir 2013, 29, $1498-1509$.

(34) Noel, S.; Liberelle, B.; Robitaille, L.; Crescenzo, G. D. Quantification of primary amine groups available for subsequent biofunctionalization of polymer surfaces. Bioconjugate Chem. 2011, 22, 1690-1699.

(35) Keszthelyi, T.; Pászti, Z.; Rigó, T.; Hakkel, O.; Telegdi, J.; Guczi, L. Investigation of solid surfaces modified by langmuir-blodgett monolayers using sum-frequency vibrational spectroscopy and X-ray photoelectron spectroscopy. J. Phys. Chem. B 2006, 110, 8701-8714.

(36) Gawalt, E. S.; Lu, G.; Bernasek, S. L.; Schwartz, J. Enhanced bonding of alkanephosphonic acids to oxidized titanium using surface-bound alkoxyzirconium complex interfaces. Langmuir 1999, 15, 8929-8933.

(37) Bonvin, D.; Bastiaansen, J. A. M.; Stuber, M.; Hofmann, H.; Ebersolda, M. M. ATP and NADPH coated iron oxide nanoparticles for targeting of highly metabolic tumor cells. J. Mater. Chem. B. 2017, 5, 8353-8365.

(38) Tudisco, C.; Oliveri, V.; Cantarella, M.; Vecchio, G.; Condorelli, G. G. Cyclodextrin anchoring on magnetic $\mathrm{Fe}_{3} \mathrm{O}_{4}$ nanoparticles modified with phosphonic linkers. Eur. J. Inorg. Chem. 2012, 22, 5323-5331.

(39) Textor, M.; Ruiz, L.; Hofer, R; Rossi, A.; Feldman, K.; Hähner, G.; Spencer. N. D. Structural chemistry of self-assembled monolayers of octadecylphosphoric acid on tantalum oxide surfaces. Langmuir 2000, 16, 3257-3271. 
(40) Bai, R.; Xue, L.; Dou, R.; Meng, S.; Xie, C.; Zhang, Q.; Guo, T.; Meng, T. Light-triggered release from pickering emulsions stabilized by $\mathrm{TiO}_{2}$ nanoparticles with tailored wettability. Langmuir 2016, 32, 9254-9264.

(41) Alexander, M. R.; Short, R. D.; Jones, F. R.; Michaeli, W.; Blomfield, C. J. A study of $\mathrm{HMDSO} / \mathrm{O}_{2}$ plasma deposits using a high-sensitivity and -energy resolution XPS instrument: curve fitting of the Si2p core level. Appl. Surf. Sci. 1999, 137,179-183.

(42) White, L. D.; Tripp, C. P. Reaction of (3-aminopropyl)dimethylethoxysilane with amine catalysts on silica surfaces. J. Colloid Interface Sci. 2000, 232, 400-407.

(43) Benítez, J. J.; Kopta, S.; Ogletree, D. F.; Salmeron. M. Preparation and characterization of self-assembled monolayers of octadecylamine on mica using hydrophobic solvents. Langmuir 2002, 18, 6096-6100.

(44) Mani, G.; Johnson, D. M.; Marton, D.; Dougherty, V. L.; Feldman, M. D.; Patel, D.; Ayon, A. A.; Agrawal, C. M. Stability of self-assembled monolayers on titanium and gold. Langmuir 2008, 24, 6774-6784.

(45) Giza, M.; Thissen, P.; Grundmeier. G. Adsorption kinetics of organophosphonic acids on plasma-modified oxide-covered aluminum surfaces. Langmuir 2008, 24, 8688-8694.

(46) Wapner, K.; Stratmann, M.; Grundmeier. G. Structure and stability of adhesion promoting aminopropyl phosphonate layers at polymer/aluminium oxide interfaces. Int. J. Adhes. Adhes. 2008, 28, 59-70.

(47) Sang, L.; Knesting, K. M.; Bulusu, A.; Sigdel, A. K.; Giordano, A. J.; Marder, S. R.; Berry, J. J.; Graham, S.; Ginger, D. S.; Pemberton. J. E. Effect of time and deposition method on 
quality of phosphonic acid modifier self-assembled monolayers on indium zinc oxide. Appl. Surf. Sci. 2016, 389, 190-198.

(48) Longo, R. C.; Cho, K.; Schmidt, W. G.; Chabal, Y. J.; Thissen. P. Monolayer doping via phosphonic acid grafting on silicon: microscopic insight from infrared spectroscopy and density functional theory calculations. Adv. Funct. Mater. 2013, 23, 3471-3477.

(49) Palma, R. D.; Laureyn, W.; Frederix, F.; Bonroy, K.; Pireaux, J. J.; Borghs, G.; Maes, G. Formation of dense self-assembled monolayers of (n-decyl)trichlorosilanes on $\mathrm{Ta} / \mathrm{Ta}_{2} \mathrm{O}_{5}$. Langmuir 2007, 23, 443-451.

(50) Laureyn, W.; Nelis, D.; Gerwen, P. V.; Baert, K.; Hermans, L.; Magnee, R.; Pireaux, J. J.; Maes, G. Nanoscaled interdigitated titanium electrodes for impedimetric biosensing. Sensors and Actuators B 2000, 68, 360-370.

(51) Ganguly, A.; Sharma, S.; Papakonstantinou, P.; Hamilton. J. Probing the thermal deoxygenation of graphene oxide using high-resolution in situ X-ray-based spectroscopies. $J$. Phys. Chem. C 2011, 115, 17009-17019.

(52) Yang, Y.; Yan, W.; Jing. C. Dynamic adsorption of catechol at the goethite/aqueous solution interface: a molecular-scale study. Langmuir 2012, 28, 14588-14597.

(53) Lereau, M.; Fournier-Wirth, C.; Mayen, J.; Farre, C.; Meyer, A.; Dugas, V.; Cantaloube, J. F.; Chaix, C.; Vasseur, J. J.; Morvan, F. Development of innovative and versatile polythiol probes for use on ELOSA or Eeectrochemical biosensors: application in hepatitis C virus genotyping. Anal. Chem. 2013, 85, 9204-9212. 
(54) Philippin, G.; Delhalle, J.; Mekhalif, Z. Comparative study of the monolayers of $\mathrm{CH}_{3}-$ $\left(\mathrm{CH}_{2}\right) \mathrm{n}-\mathrm{SiCl}_{3}$ and $\mathrm{CH}_{3}-\left(\mathrm{CH}_{2}\right) \mathrm{n}-\mathrm{PO}(\mathrm{OH})_{2}, \mathrm{n}=4$ and 13 , adsorbed on polycrystalline titanium substrates. Appl. Surf. Sci. 2003, 212-213, 530-536.

(55) Stevens, M. J. Thoughts on the structure of slkylsilane monolayers. Langmuir 1999, 15, $2773-2778$.

(56) Kanta, A.; Sedev, R.; Ralston, J. The formation and stability of self-assembled monolayers of octadecylphosphonic acid on titania. Colloids Surf. Physicochem. Eng. Asp. 2006, 291, 5158.

(57) Jo, K.; Yang, H. Comparative study of stability of phosphonate self-assembled monolayers on indium-tin oxide electrodes prepared using different methods. J Electroanal Chem. 2014, $712,8-13$.

(58) Jo, K.; Yu, H.; Yang, H. Formation kinetics and stability of phosphonate self-assembled monolayers on indium-tin oxide. Electrochimica Acta 2011, 56, 4828-4833.

(59) Bhure, R.; Mahapatro, A.; Bonner, C.; Abdel-Fattah, T. M. In vitro stability study of organophosphonic self assembled monolayers (SAMs) on cobalt chromium ( $\mathrm{Co}-\mathrm{Cr}$ ) alloy. Mater. Sci. Eng. C 2013, 33, 2050-2058.

(60) Bhure, R.; Abdel-Fattah, T. M.; Bonner, C.; Hallc, F.; Mahapatro, A. Stability of phosphonic self assembled monolayers (SAMs) on cobalt chromium (Co-Cr) alloy under oxidative conditions. Appl. Surf. Sci. 2011, 257, 5605-5612.

(61) Thissen, P.; Valtiner, M.; Grundmeier, G. Stability of phosphonic acid self-assembled monolayers on amorphous and single-crystalline aluminum oxide surfaces in aqueous solution. Langmuir 2010, 26, 156-164. 
(62) Dubey, M.; Weidner, T.; Gamble, L. J.; Castner, D. G. Structure and order of phosphonic acid-based self-assembled monolayers on Si (100). Langmuir 2010, 26, 14747-14754.

(63) Anderson, T. H.; Yu, J.; Estrada, A.; Hammer, M. U.; Waite, J. H.; Israelachvili. J. N. The contribution of DOPA to substrate-peptide adhesion and internal cohesion of mussel-inspired synthetic peptide films. Adv. Funct. Mater. 2010, 20, 4196-4205.

(63) Palazon, F., Rojo-Romeo, P., Chevalier, C., Géhin, T., Belarouci, A., Cornillon, A., Zuttion, F., Phaner-Goutorbe, M., Souteyrand, E., Chevolot, Y. \& Cloarec, J. P. Nanoparticles selectively immobilized onto large arrays of gold micro and nanostructures through surface chemical functionalizations. J. Colloid Interf. Sc. 2015, 447, 1, 152-158.

(64) Zhang, J., Leonard, D., Mazurczyk, R., Monnier, V., Gehin, T., Monfray, S., Chevolot, Y. \& Cloarec, J. P. . Orthogonal chemical functionalization of patterned Au/TiW substrate for selective immobilization of nanoparticles. Nanotechnology 2019, https://doi.org/10.1088/1361-6528/ab1556

(65) Palazon, F., Montenegro Benavides, C., Léonard, D., Souteyrand, E., Chevolot, Y., \& Cloarec, J. P. . Carbodiimide/NHS derivatization of COOH-terminated SAMs: activation or byproduct formation?. Langmuir 2014, 30, 16, 4545-4550. 
For Table of Contents Use Only
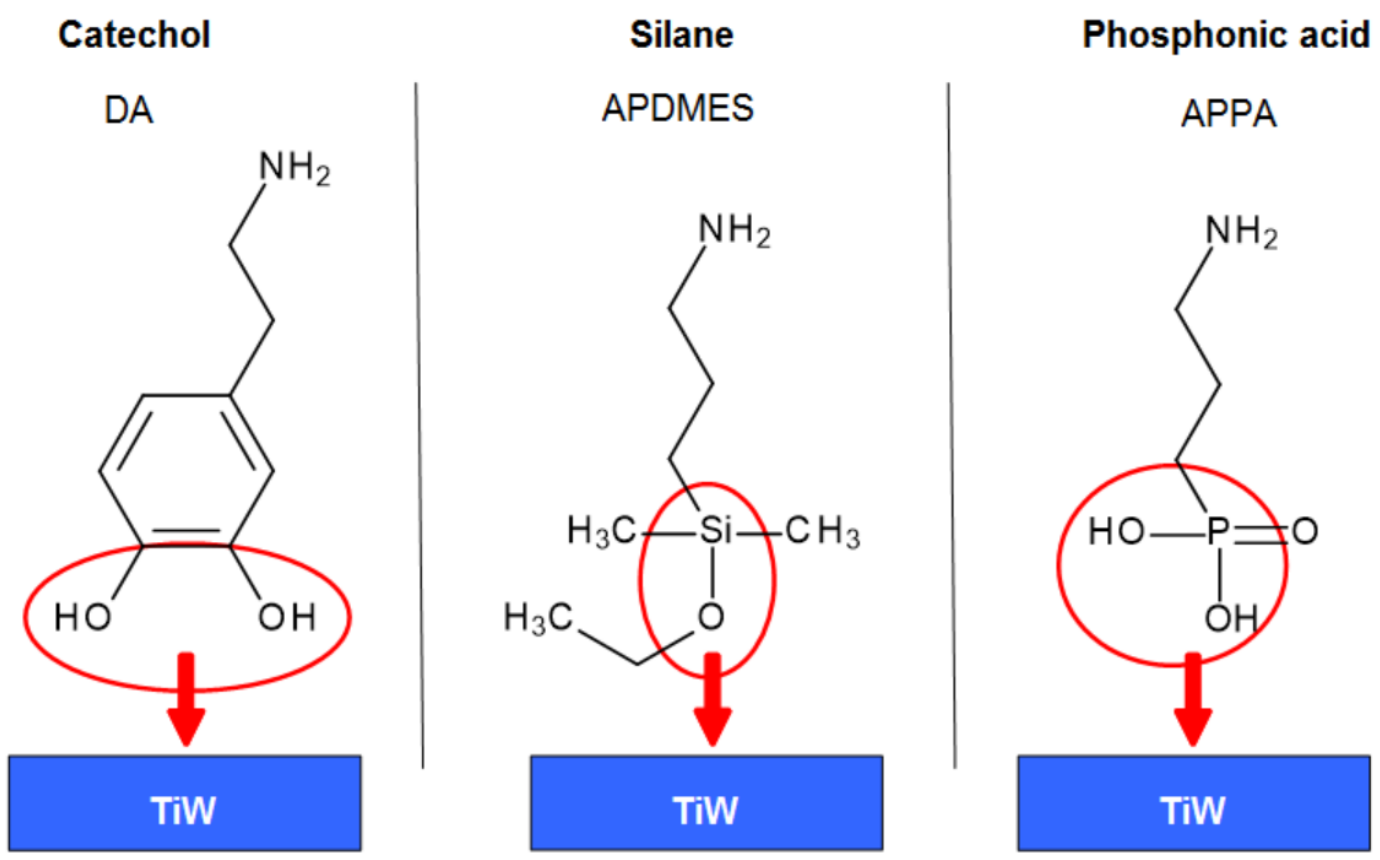


\section{Supporting information:}

\section{Oxidized titanium tungsten surface functionalization by silane, phosphonic acid or ortho-dihydroxyaryl based organolayers}

Jian Zhang,,$^{\dagger}$ Christelle Yeromonahos, ${ }^{\dagger}$ Didier Léonard, ${ }^{\dagger}$ Thomas Géhin, ${ }^{\dagger}$ Claude Botella, ${ }^{\dagger}$ Geneviève Grenet, ${ }^{\dagger}$ Aziz Benamrouche, ${ }^{\dagger}$ José Penuelas, ${ }^{\dagger}$ Stéphane Monfray, ${ }^{\S}$ Yann Chevolot,${ }^{\dagger *}$ and Jean-Pierre Cloarec ${ }^{\dagger *}$

${ }^{\dagger}$ Université de Lyon, Institut des Nanotechnologies de Lyon (INL) - UMR CNRS 5270, Ecole Centrale de Lyon, 36 Avenue Guy de Collongue, 69134 Ecully cedex, France.

¥Univ Lyon, CNRS, Université Claude Bernard Lyon 1, ENS de Lyon, Institut des Sciences Analytiques, UMR 5280, 5, rue de la Doua, F-69100 Villeurbanne, France.

${ }^{\S}$ STMicroelectronics SA, 850, rue Jean Monnet, 38926, Crolles, France.

Corresponding Author

Dr. Yann Chevolot Tel.: +33 (0) 472186058 E-mail: yann.chevolot@ec-lyon.fr

Prof. Jean-Pierre Cloarec Tel.: +33 (0) 472186252 E-mail: jean-pierre.cloarec@ec-lyon.fr 


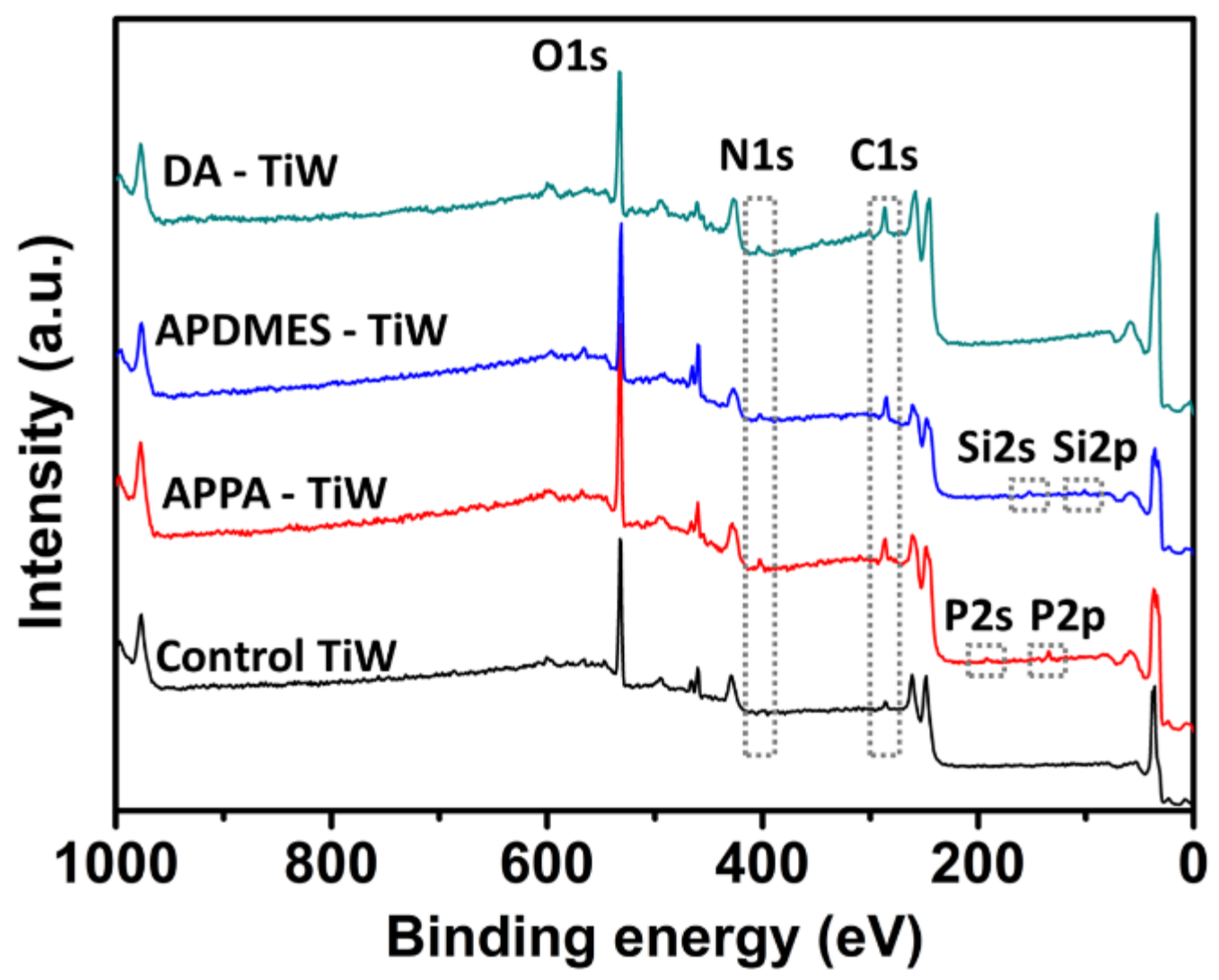

Figure S1. XPS survey scans of control TiW, APPA-TiW, APDMES-TiW and DA-TiW. 

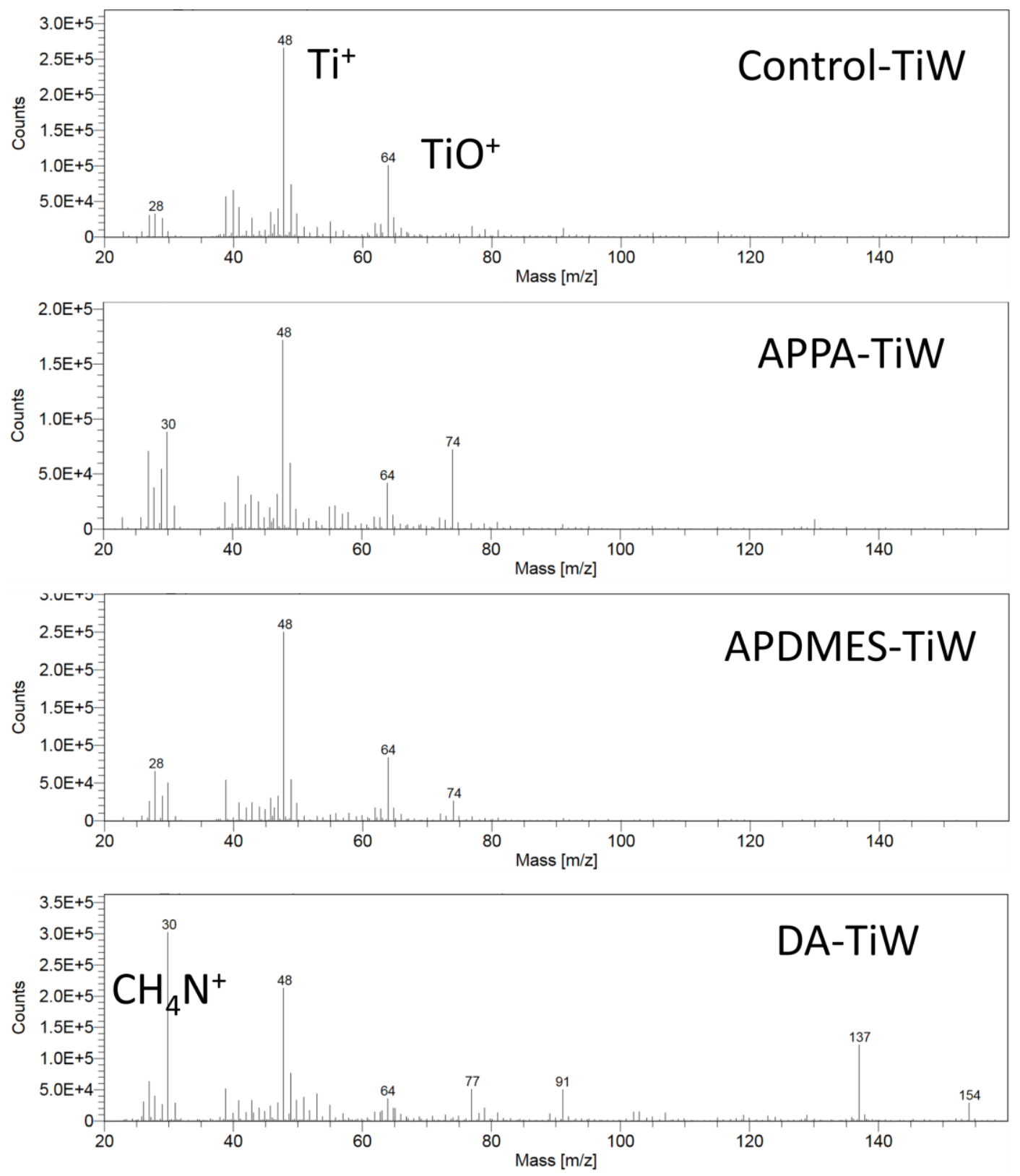

Figure S2: Positive mode ToF-SIMS spectra of control TiW, APPA-TiW, APDMES-TiW and DA-TiW in the ranges of $\mathrm{m} / \mathrm{z}=20-160$. 